\title{
Trichodiene Production in a Trichoderma harzianum erg1-Silenced Strain Provides Evidence of the Importance of the Sterol Biosynthetic Pathway in Inducing Plant Defense-Related Gene Expression
}

\author{
M. G. Malmierca, ${ }^{1}$ S. P. McCormick, ${ }^{2}$ R. E. Cardoza, ${ }^{1}$ E. Monte,${ }^{3}$ N. J. Alexander, ${ }^{2}$ and S. Gutiérrez ${ }^{1}$ \\ ${ }^{1}$ Area of Microbiology, Universitary School of Agricultural Engineers, University of León, Campus de Ponferrada. Avda, Astorga \\ s/n, 24400 Ponferrada, Spain; ${ }^{2}$ Bacterial Foodborne Pathogen and Mycology Unit, USDA/ARS, National Center for Agricultural \\ Utilization Research, Peoria, IL 61604-3902, U.S.A.; ${ }^{3}$ Spanish-Portuguese Centre of Agricultural Research (CIALE), \\ Department of Microbiology and Genetics, University of Salamanca, 37185 Salamanca, Spain
}

Submitted 9 June 2015. Accepted 10 July 2015.

Trichoderma species are often used as biocontrol agents against plant-pathogenic fungi. A complex molecular interaction occurs among the biocontrol agent, the antagonistic fungus, and the plant. Terpenes and sterols produced by the biocontrol fungus have been found to affect gene expression in both the antagonistic fungus and the plant. The terpene trichodiene (TD) elicits the expression of genes related to tomato defense and to Botrytis virulence. We show here that TD itself is able to induce the expression of Botrytis genes involved in the synthesis of botrydial (BOT) and also induces terpene gene expression in Trichoderma spp. The terpene ergosterol, in addition to its role as a structural component of the fungal cell membranes, acts as an elicitor of defense response in plants. In the present work, using a transformant of $T$. harzianum, which is silenced in the erg1 gene and accumulates high levels of squalene, we show that this ergosterol precursor also acts as an important elicitor molecule of tomato defense-related genes and induces Botrytis genes involved in BOT biosynthesis, in both cases, in a concentration-dependent manner. Our data emphasize the importance of a balance of squalene and ergosterol in fungal interactions as well as in the biocontrol activity of Trichoderma spp.

Terpenes include a large variety of compounds with diverse physiological functions. Some of them are important for mediating environmental interactions between microorganisms and plants (Gershenzon and Dudareva 2007) by acting on the regulation of functions in both partners. The trichothecenes are a particular class of terpenes that have attracted special attention, since they are important mycotoxins for plants and, also, for animals and humans (Cano et al. 2013; Pestka and Smolinski 2005). Trichothecenes are sesquiterpenoid compounds produced by a plethora of fungi belonging to the genera Fusarium, Trichothecium, Myrothecium, Stachybotrys, and Trichoderma, and among them, the Fusarium trichothecenes are the most studied and characterized (Cole et al. 2003; Degenkolb et al. 2008; McCormick et al. 2011).

Corresponding author: S. Gutiérrez; E-mail: s.gutierrez@unileon.es

*The $\boldsymbol{e}$-Xtra logo stands for "electronic extra" and indicates that five supplementary figures are published online.

(c) 2015 The American Phytopathological Society
The Trichoderma trichothecenes, harzianum A (HA) and trichodermin are produced by $T$. arundinaceum and $T$. brevicompactum, respectively (Nielsen et al. 2005). While trichodermin is highly toxic for plants (Tijerino et al. 2011), HA does not show any 'in vivo' phytotoxic activity (Malmierca et al. 2012). Thus, T. arundinaceum has been used as a model of a Trichoderma strain producing trichothecenes without the 'in vivo' toxicity associated with these compounds. Recently, the role of HA in the induction of plant defense responses as well as in the antagonistic antifungal activity of this fungus has been described (Malmierca et al. 2012). In addition to these functions, the role of trichothecenes in the regulation of the intracellular pool of farnesyl diphosphate (FPP) has also been proposed, indicating an important function of trichothecenes in fungal physiology in spite of their activities as antifungal or as plant defense inducers (Asadollahi et al. 2010; Malmierca et al. 2013, 2015a and b).

FPP is a common precursor in the biosynthetic pathways of terpenes, sterols, trichothecenes, and other similar compounds. In the trichothecene biosynthetic pathway, FPP is cyclized by trichodiene synthase, encoded by tri5 (Hohn and Beremand 1989), to form trichodiene (TD), the hydrocarbon volatile precursor of trichothecenes. Terpene volatile compounds (VOC) have been indicated in the regulation of functions in organisms other than the parental producer. For example, TD has been shown to affect the induction of plant defense-related (PDR) genes as well as the plant architecture. When a non-trichothecene producing fungus (T. harzianum) was transformed with tri5, the production of TD resulted in an upregulation of tomato PDR genes by this fungus and also in a reduction of the lateral growth of secondary roots. In addition, transformants overexpressing this gene had reduced levels of ergosterol, presumably by the redirection of FPP to TD, without affecting the level of squalene (Malmierca et al. 2015b).

Ergosterol has been described as an important elicitor of plant defense responses (Dixon and Lamb 1990; Klemptner et al. 2014; Rossard et al. 2010) and has been shown to specifically induce the generation of an oxidative burst in cotyledons of Mimosa pudica (Rossard et al. 2006). In addition, several lines of evidence support the role of jasmonate (JA)-signaling in the ergosterol-elicitation response (Chandra et al. 1996; Chapman 1998; Gomès et al. 2003; Lee et al. 1997). Biosynthesis of sterols is tightly regulated at several levels, as HMGR and Erg9 are two key enzymes in the pathway (Asadollahi et al. 2010; Takahashi et al. 1999) that catalyze the biosynthesis of mevalonic acid and 
squalene, respectively. Interestingly, repression of ERG9 gene in yeast resulted in an increase in the production of the sesquiterpene cubebol and also in an unexpected accumulation of squalene, without modification of ergosterol levels, in comparison with the wild-type strain (Asadollahi et al. 2010). Squalene, a key intermediate in the sterol biosynthesis, is a highly hydrophobic neutral lipid, whose accumulation has been associated with the clustering of lipid droplets in yeast, which contain, in addition to squalene, triacylglycerols and steryl esters (Spanova et al. 2012; Ta et al. 2012). Squalene can also be located in the cell membranes, including the plasma membrane, and it appears that the level of squalene and ergosterol affects the fluidity or rigidity of the membranes, with squalene increasing the rigidity in fluid membranes and increasing the fluidity in rigid membranes (Spanova et al. 2012). However, despite this important structural function, the role of squalene in other physiological functions has not been reported. Thus, in the present work and based on background results, a mutant of Trichoderma harzianum silenced in ergl, which accumulates lower levels of ergosterol when grown in media containing the antimycotic compound terbinafine (Cardoza et al. 2006b), was used to overexpress the T. arundinaceum tri5 gene, in order to determine how ergl silencing affects the level of TD production. This also allowed us to determine the effect of TD production on the induction of PDR genes, in an attempt to establish a possible role of squalene as an elicitor of plant defense responses and Botrytis virulence genes. Finally, the effect of tri5 overexpression on the pattern of production of other sesquiterpene compounds was studied.

\section{RESULTS}

\section{Isolation of an E20 transformant overexpressing the tri5 gene.}

Protoplasts of the T. harzianum erg 1-silenced E20 strain were transformed with the constructed plasmid pANT5-F carrying tri5 from T. arundinaceum. A total of 20 transformants were isolated by resistance to $100 \mu \mathrm{g}$ of hygromycin per milliliter, followed by three stabilization rounds in which the presence of hygromycin at a concentration of $200 \mu \mathrm{g} \mathrm{ml}^{-1}$ (rounds 1 and 3) and media without antibiotic (round 2) were alternated. Polymerase chain reaction (PCR) and Southern studies were carried out with nine of those transformants, and one of them, E20-tri5.7, showing the expected pattern (Supplementary Fig. S1) was selected for further study.

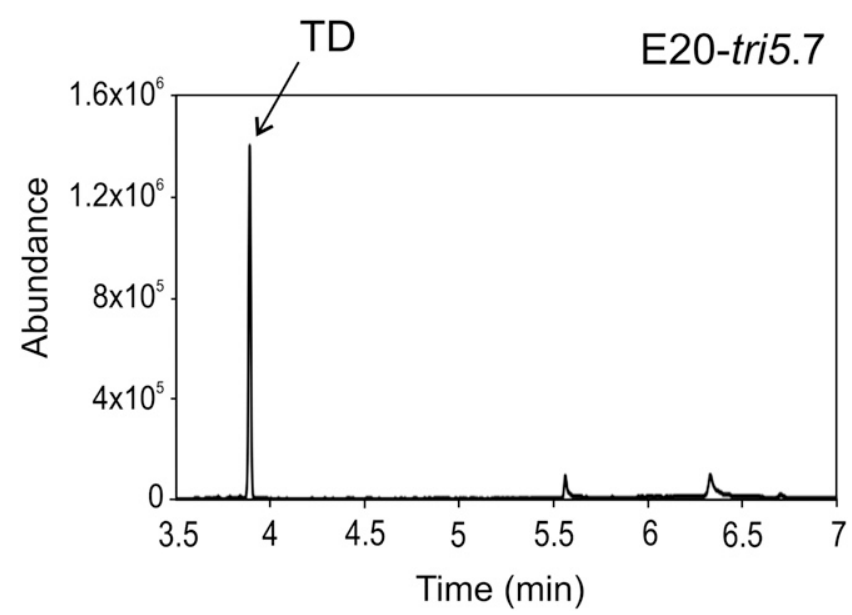

Fig. 1. Gas chromatography-mass spectrometry analysis of E20-tri5-7 transformant. Trichodiene (TD) was detected at $3.89 \mathrm{~min}$.

\section{Identification and quantification of terpenes from cultures.}

TD was detected and quantified in cultures of the selected transformant (Fig. 1) (Supplementary Fig. S2A). E20-tri5.7 produced $38 \pm 1.3 \mu \mathrm{g} \mathrm{ml}^{-1}$ of TD in 8-day-old cultures in YEPD (yeast extract, peptone, and glucose) broth. TD was also identified and quantified from the headspace of E20-tri5.7 plates grown on PDA medium (Fig. 2) for 24 or $72 \mathrm{~h}$. The amounts of TD captured were 2,455 and $3,258 \mu \mathrm{g}$, respectively.

In addition to TD, other VOC were detected in the chromatograms. One of them, identified as spiro[4,5] dec-8-en-7-ol 4,8-dimethyl-1(1-methylethyl) (SQ) (Fig. 2), had levels inversely proportional to those of TD. Thus, the area of the peak for the spiro SQ compound was of 8,174 and 5,226 in the headspace trapped from the E20-tri5.7 strain grown for 24 and $72 \mathrm{~h}$, respectively, while the area of the peaks for the same compound trapped from E20-pAN71 (control) headspace were of 11,891 and 16,265 at 24 and $72 \mathrm{~h}$, respectively. Note that the control, i.e., E20-pAN71, does not produce TD. Another sesquiterpenoid, which on the basis of mass spectral fragmentation appeared to be related to TD, was detected at $4.9 \mathrm{~min}$ (Fig. 2, asterisk).

\section{Effect of VOC produced by E20-pAN71 and E20-tri5.7 transformants on plant phenotype.}

A comparison of aerial and root growth from tomato plants treated with VOC from either E20-pAN71 or E20-tri5.7 showed that the high level of one or more TD or other VOC produced by E20-tri5.7 markedly reduced both aerial and lateral root growth (Fig. 3A and B). In order to determine the effect of VOC produced by the strains used in this study on the expression of tomato PDR genes, RNAs were extracted from the aerial part of the tomato plants grown in the presence of VOC.

Production of VOC by E20-tri5.7 resulted in a strong induction of the five genes analyzed. $P R 1 b 1$ and $P R-P 2$, both related to the salicylic acid (SA) pathway, had very high relative expression values of $1,559.510-(P=0.032)$ and $266.576-(P=0.032)$ fold, respectively (Fig. 3D), in comparison with the level of expression in plants grown without the presence of Trichoderma VOC $\left(\mathrm{H}_{2} \mathrm{O}\right.$ condition). The JA/ethylene (ET)-related genes analyzed in the present work were also upregulated, having expression ratios ranging from 12.921- to 34.708-fold for PINI and PINII, respectively (Fig. 3D). TomLoxA expression values were raised 31.326-fold.

The analysis of the expression ratio among plants grown in the presence of E20-tri5.7 VOC versus plants grown in the presence of those compounds produced by control strain E20pAN71 showed that all marker genes were upregulated, with ratios of expression ranging from 15.696-fold for TomLoxA to 491.351-fold for PINII (Fig. 3E). Thus, TD produced by E20tri5.7 repressed aerial and lateral root growth and upregulated expression of all the tomato PDR genes analyzed.

\section{Expression of other terpene genes was affected by the production of TD.}

Expression of other key terpene genes was examined in E20tri5.7 to determine the effect of TD production in the general regulation of Trichoderma terpene biosynthetic genes (Fig. 4C). Gene expression studies from 96-h-grown mycelia showed that $h m g R$, ergl, and erg7 genes were upregulated in this transformant, compared with the E20-pAN71 control strain, by factors ranging from 1.232 -fold $(P=0.000)$ for $h m g R$ to 3.440 fold $(P=0.000)$ for $\operatorname{erg} 1$ (Fig. 4A).

In addition, the upregulation of $\operatorname{erg} 1$, encoding the squalene epoxidase enzyme, corresponded with the increase in the resistance to terbinafine (TRB) of the E20-tri5.7 transformant in comparison with the E20-pAN71 control strain (Fig. 4B). 
Production of TD significantly affected the level of squalene accumulation.

Production of ergosterol and squalene was quantified in 24and 96-h cultures of T34-43b1.3 and E20-pAN71 (controls) and E20-tri5.7 and T34-SIL-E7 transformants. At $96 \mathrm{~h}$, the level of ergosterol in E20-tri5.7 was not significantly different in comparison with the parental strain, E20-pAN71, and both were markedly less than the control T34-43b1.3. At $96 \mathrm{~h}$, the level of squalene in the E20-pAN71 and E20-tri5.7 strains, both silenced in $\operatorname{erg} 1$ ( $\mathrm{erg} 1$-si) was increased by 424 and $370 \%$, respectively, in comparison with the T34-43b1.3 control strain (Table 1A). This suggests that silencing ergl is the main factor leading to the accumulation of squalene in these strains. The additional expression of tri5 in the silenced mutant slightly reduced the levels of squalene (about 10\%), suggesting that part of the FPP pool was channeled toward TD instead of toward squalene. In the case of the T34-SIL-E7 transformant, silenced in the erg7 gene (erg7-si) and used only for comparative purposes, both compounds squalene and ergosterol were significantly reduced (65 and 56\%, respectively) when analyzed in 96-h-grown mycelia, as compared with T34-43b1.3.

In general, when production of squalene and ergosterol was quantified from mycelia detached from roots of tomato plants grown in hydroponic cultures, the differences in the production of these two compounds versus the production in T34-43b1.3 were maintained at similar levels to those observed in 96-h potato dextrose broth (PDB)-grown cultures (Table 1B). However some differences can be observed in the production of squalene by detached mycelia of E20-tri5.7, which has an increase of $639 \%$ over that seen in detached mycelia of T34-43b1.3 and an increase over that seen in E20-tri5.7 grown in PDB medium. Detached mycelia of T34-SIL-E7 produce lower amounts of squalene and ergosterol than that seen in detached mycelia of T34-43b1.3, yet the reduction is not as great as that seen in the PDB cultures. These data suggest that an interaction of TD produced by E20tri5.7 with tomato roots stimulates an accumulation of squalene and ergosterol (Table 1B).

In order to analyze if there is some amount of ergosterol or squalene that is being released to the culture medium, these compounds were quantified from Murashige and Skoog (MS) broths of tomato hydroponic cultures and were inoculated with or without the different Trichoderma strains used in the present work. In total, five broths were analyzed: i) MS+tomato+T34-43b1.3; ii) MS+tomato+E20-pAN71; iii) MS+tomato+E20-tri5.7; iv) MS+ tomato+T34-SIL-E7; and v) MS+tomato without Trichoderma strains. Even when quantification was carried out with the highest concentration possible, these compounds were not detected, indicating that they are not secreted to the medium, at least not in detectable amounts.

For comparison of Trichoderma ergosterol or squalene production to other antagonistic fungi, measurements were made on Myrothecium roridum, Botrytis cinerea, and Fusarium sporotrichoides cultures grown for $96 \mathrm{~h}$ in PDB medium. Levels of squalene $(\mathrm{S})$ varied from a low of $0.03 \mathrm{mg}$ of squalene per gram of dry weight (mg S/g DW) in F. sporotrichioides to $0.096 \mathrm{mg} \mathrm{S} / \mathrm{g}$ DW in T34-43b1.3 (Table 2) while ergosterol levels ranged from a low of $3.926 \mathrm{mg}$ of ergosterol per gram of DW (mg E/g DW) in B. cinerea to $6.707 \mathrm{mg} \mathrm{E} / \mathrm{g} \mathrm{DW}$ in F. sporotrichioides.

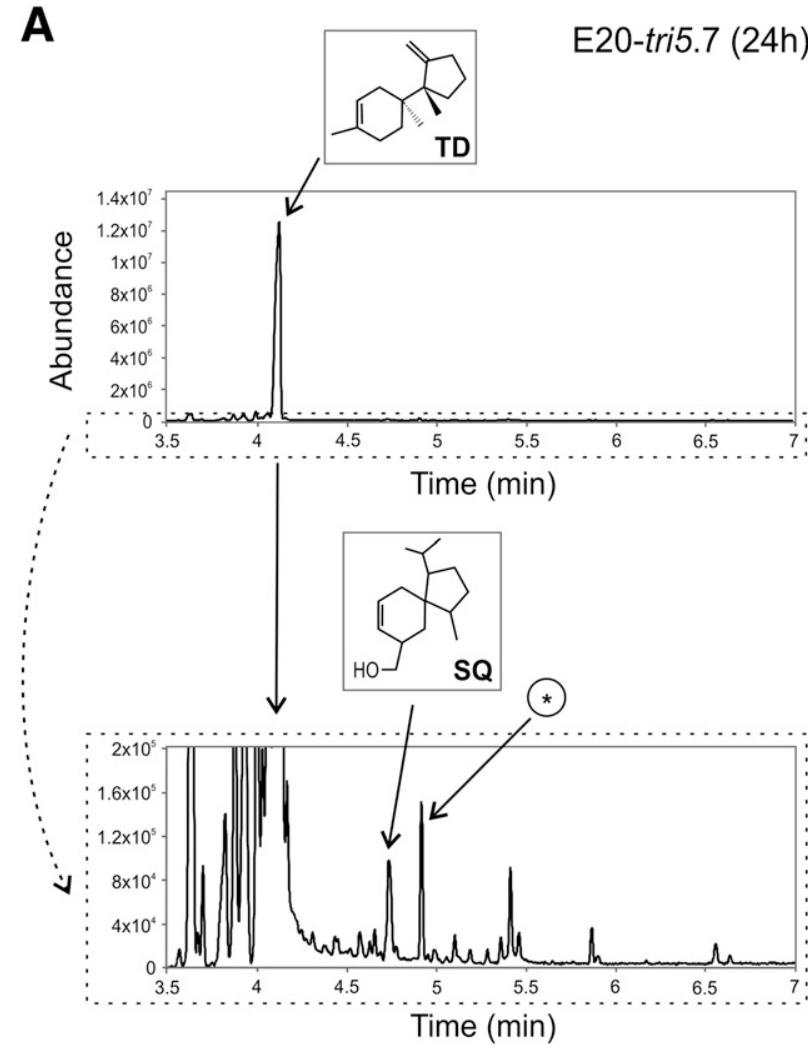

B

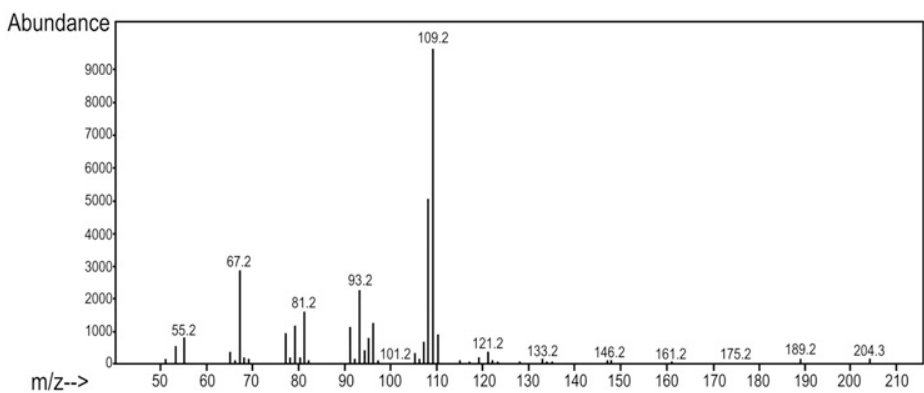

C

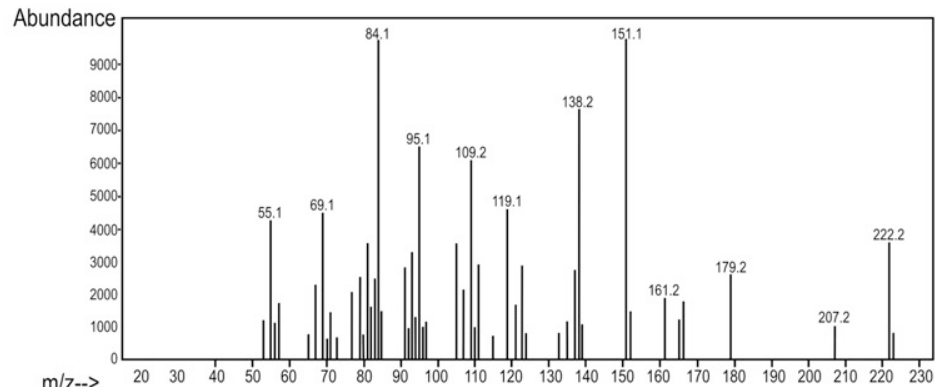

Fig. 2. A, Gas chromatography-mass spectrometry analysis of VOC captured over a period of 4 days from headspace of the E20-tri5-27 strain previously grown on MEA ( $2 \%$ glucose, $2 \%$ malt extract, $1 \%$ peptone, $2 \%$ agar, $\mathrm{pH} 5.6$ ) plates for $24 \mathrm{~h}$. Trichodiene (TD) detected at 4.13 min has been indicated with an arrow. In the lower panel there is also indicated a sesquiterpene (SQ) detected at approximately 4.8 min, identified as spiro[4,5] dec-8-en-7-ol 4,8-dimethyl-1(1methylethyl), whose level was reduced in the E20-tri5.7 transformant in comparison with the control E20-pN71 strain. The asterisk with the arrow calls attention to an unidentified TD-related sesquiterpene that was detected at $4.9 \mathrm{~min}$. B, Mass spectra of TD and $\mathbf{C}$, of SQ. Note that these mass spectra were extracted from total ion chromatogram peaks at $4.13 \mathrm{~min}$ and $4.8 \mathrm{~min}$ for TD and SQ, respectively. 
Effect of TD production on the expression of $B$. cinerea B05.10 and Trichoderma genes in confrontation experiments.

Confrontation experiments determined the effect of tri5 expression on the expression of B05.10 virulence genes. Expression of tri5 basically did not affect expression of the B05.10 virulence genes analyzed in mycelia isolated from confrontation experiments between B05.10 vs. E20-tri5.7 in comparison with the confrontation vs. E20-pAN71. Only BcBOT5, BcBOT4, and sodl were slightly downregulated, with ratios of expression of

\section{A E20-pAN71}

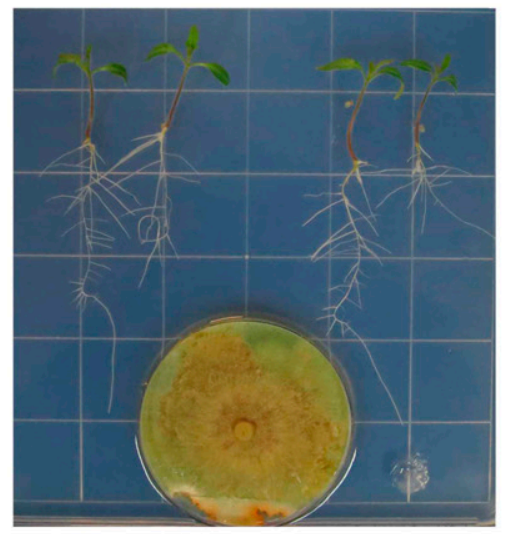

C

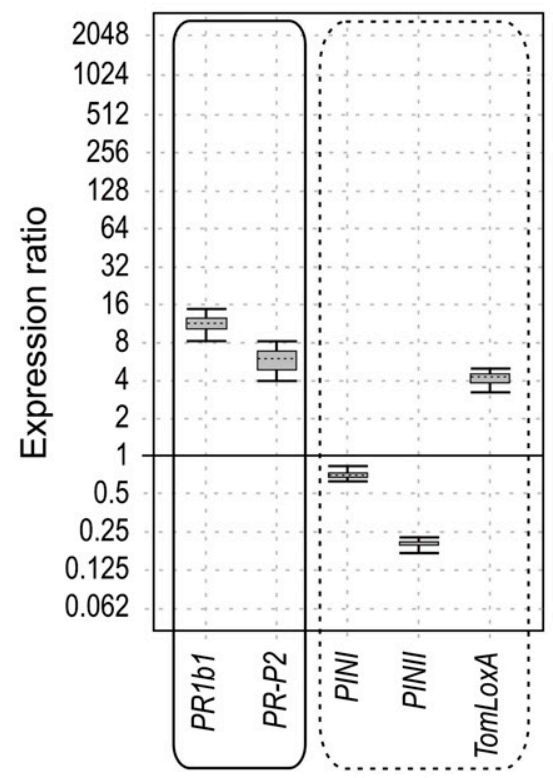

Gene

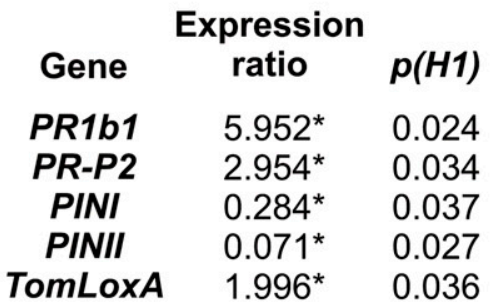

B $\quad$ E20-tri5.7

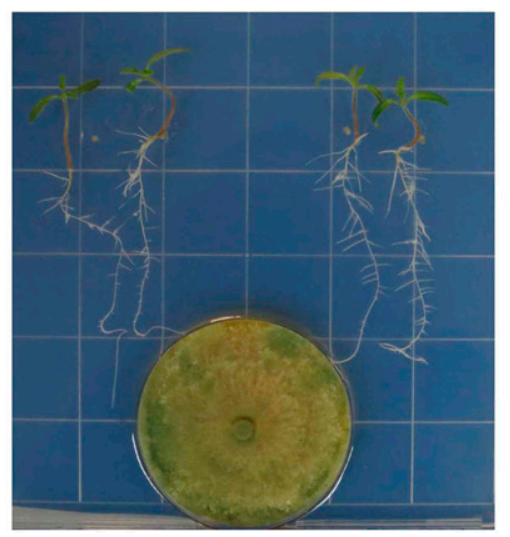

D

+E20-tri5.7 vs $\mathrm{H}_{2} \mathrm{O}$

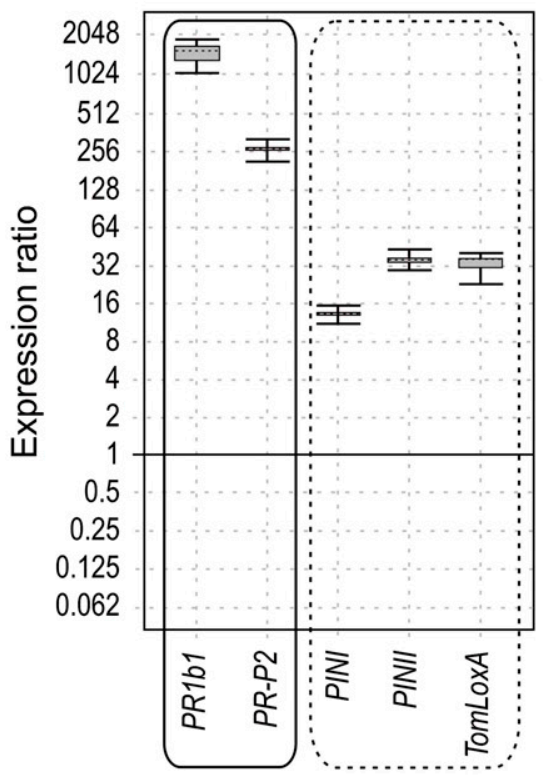

Gene

$\begin{array}{ccc}\text { Eene } & \begin{array}{c}\text { Expression } \\ \text { ratio }\end{array} & \boldsymbol{p}(\boldsymbol{H} 1) \\ \text { PR1b1 } & 1559.510^{*} & 0.032 \\ \text { PR-P2 } & 266.576^{*} & 0.032 \\ \text { PINI } & 12.921^{*} & 0.032 \\ \text { PINII } & 34.708^{*} & 0.032 \\ \text { TomLoxA } & 31.326^{*} & 0.032\end{array}$

E +E20-tri5.7 vs E20-pAN71

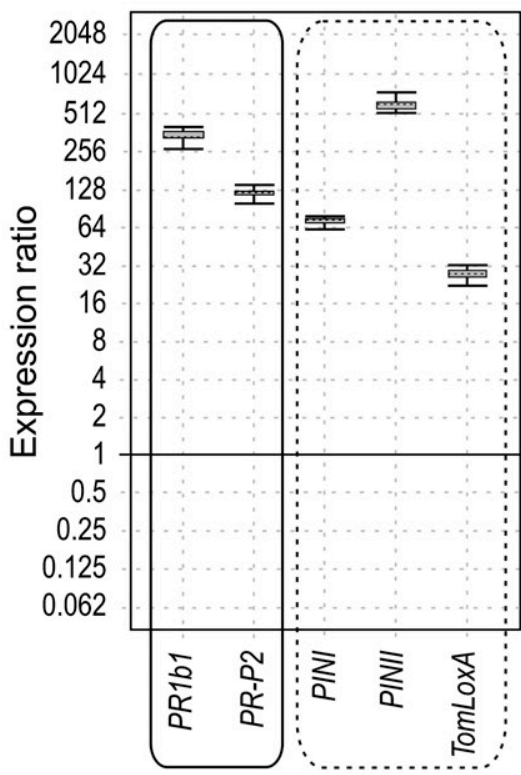

Gene

$\begin{array}{crc}\text { Gene } & \begin{array}{c}\text { Expression } \\ \text { ratio }\end{array} & \boldsymbol{p}(\boldsymbol{H} 1) \\ \text { PR1b1 } & 261.998^{*} & 0.032 \\ \text { PR-P2 } & 81.834^{*} & 0.000 \\ \text { PINI } & 45.546^{*} & 0.000 \\ \text { PINII } & 491.351^{*} & 0.000 \\ \text { TomLoxA } & 15.696^{*} & 0.000\end{array}$

Fig. 3. Effects of volatile compounds produced by A, E20-pAN71 and B, E20-tri5.7 strains. C and D, Quantitative polymerase chain reaction analysis of the relative level of expression of five tomato defense-related genes in the aerial parts of tomato plants grown under the effect of volatiles produced by E20-pAN71 (C) and E20-tri5.7 (D) in comparison with plants grown without Trichoderma volatiles. E, Level of expression of those tomato defense-related genes in plants under the effect of E20-tri5-7 volatiles versus the levels of expression in plants grown in the presence of E20-pAN71 volatiles. The expression ratios as well as the statistical probability values were calculated using the REST program (Pfaffl et al. 2002). Numeric data are illustrated at the bottom and are indicated with an asterisk and squared in the graphic representation for those that were statistically significant $(P<0.05)$. Boxes with full line indicate salicylic acid-related genes with statistically significant differences; boxes with dotted line indicate jasmonate-related genes with statistically significant differences. 
0.818- $(P=0.000), 0.645-(P=0.000)$, and $0.429-(P=0.000)$ fold, respectively (Fig. 5B).

Although tri5 expression does not have much effect on $\mathrm{Bo}$ trytis virulence genes, the presence of T. harzianum E20 does, as shown by the confrontations of B05.10 versus E20-pAN71 (empty plasmid) or E20-tri5.7. All the BcBOT genes were upregulated when compared against the level of expression in B05.10 growing alone (Supplementary Fig. S3). For the other Botrytis virulence genes, sodl and atrB were up- and downregulated, respectively, and the expression of $b m p l$ and $p g l$ was not or was just slightly affected in both confrontation assays.

When gene expression of $T$. harzianum terpene-related genes was analyzed in the presence of B05.10, $h m g R, \operatorname{erg} 9, \operatorname{erg} 7$, and dppl were all slightly downregulated (Fig. 5C) in the presence of tri5 expression. However, when comparing terpene biosynthetic gene expression between E20-tri5.7 and E20-pAN71 without the presence of B05.10 (Fig. 4A), tri5 expression upregulated $h m g R$, ergl, and $\operatorname{erg} 7$ (Fig. 4A). This suggests that some kind of interaction between B05.10 and TD downregulates terpene gene expression.
TD itself slightly upregulates expression of $B c B O T$ genes.

When the effect of TD production on the expression of B05.10 virulence genes was examined in a VOC assay, it was determined that volatiles, including TD, produced by E20tri5.7 upregulated slightly but significantly the expression of $B C B O T$ genes. The expression of these genes produced relative values between $1.178(P=0.023)$ for $B c B O T 4$ and $2.076(P=0.000)$ for $B c B O T 1$ (Fig. 6). This level of upregulation was much lower than that observed in the confrontation of B05.10 vs. E20-pAN71 or E20-tri5.7, which would explain why an effect from the presence of tri5 (and production of TD) was not detected in the confrontation studies with E20-tri5.7 or E20-pAN71, since the background strain itself upregulates that expression at a much higher level.

Volatile TD production downregulated expression of $\operatorname{atr} B$ and $\operatorname{pg} 1$, with relative expression ratios of $0.640(P=$ $0.000)$ and $0.469(P=0.000)$, respectively, while the expression of sodl and pgl were not affected by TD production (Fig. 6).

\section{A $96 \mathrm{~h}$ E20-tri5.7 vs. E20-pAN71}
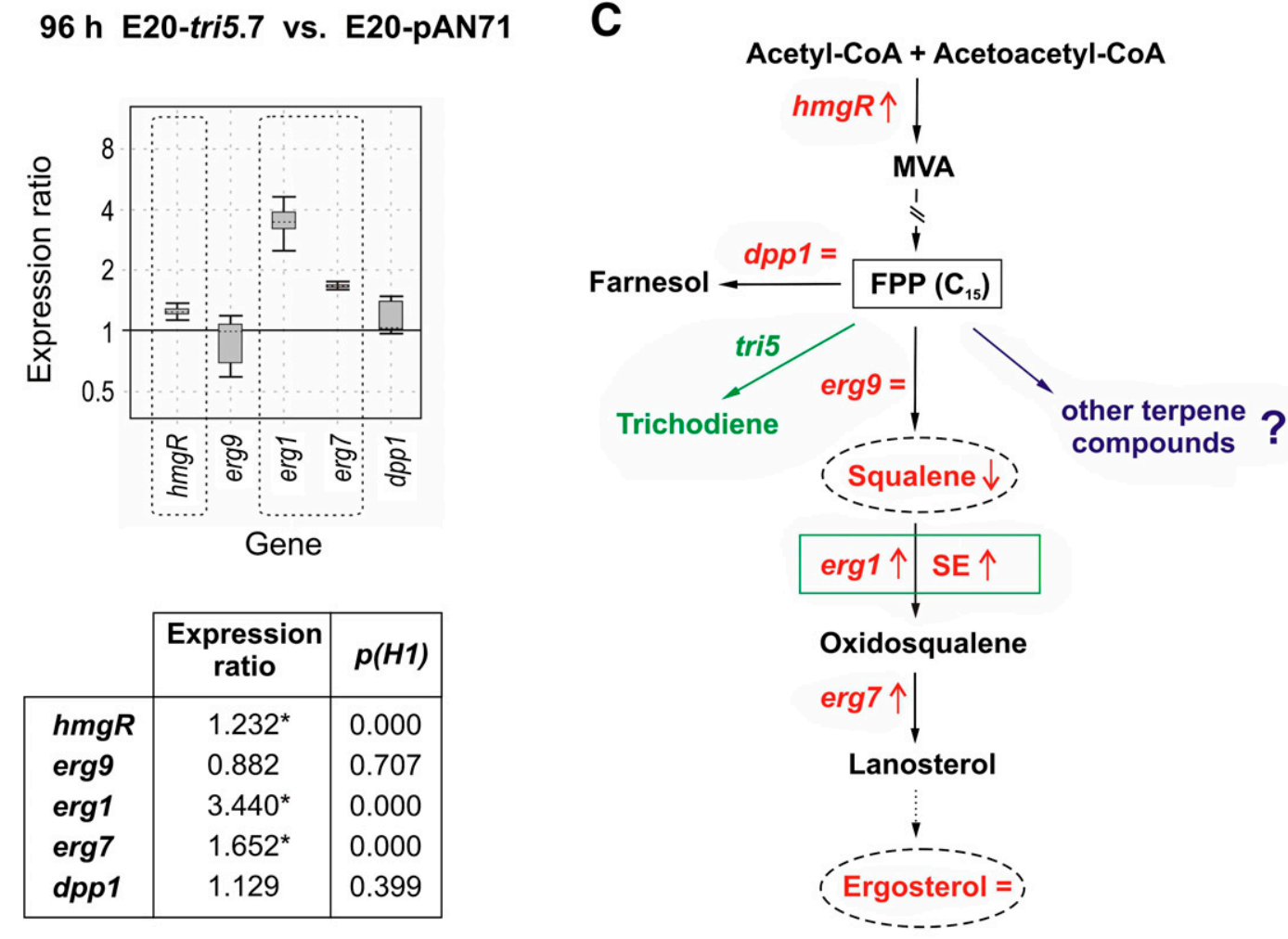

B

\begin{tabular}{|l|l|l|}
\cline { 2 - 3 } \multicolumn{1}{c|}{} & $\begin{array}{c}\text { Expression } \\
\text { ratio }\end{array}$ & $\boldsymbol{p}(\boldsymbol{H 1})$ \\
\hline hmgR & $1.232^{*}$ & 0.000 \\
erg9 & 0.882 & 0.707 \\
erg1 & $3.440^{*}$ & 0.000 \\
erg7 & $1.652^{*}$ & 0.000 \\
dpp1 & 1.129 & 0.399 \\
\hline
\end{tabular}

Oxidosqualene

\begin{tabular}{|lll|l|l|}
\hline TRB $\mu \mathrm{g} / \mathrm{ml}$ & 0 & 0.1 & 1 & 2.5 \\
\hline E20-pAN71 & & & & \\
E20-tri5.7 & & & & \\
\hline
\end{tabular}

Fig. 4. A, Quantitative polymerase chain reaction analysis of the relative level of expression of the $h m g R$, erg 9 , erg 1 , erg7, and $d p p 1$ genes in transformant E20-tri5-7 grown for $96 \mathrm{~h}$, in comparison with strain E20-pAN71. Boxes with dotted lines indicate genes with statistically significant differences. B, Analysis of the terbinafine (TRB) resistance of the E20-tri5.7 transformant, compared with the E20-pAN71 control strain. TRB concentrations are indicated above each plate. C, Schematic representation of the changes observed in the level of expression of the terpene genes analyzed and in the level of ergosterol and squalene as result of tri5 gene expression in 96-h-grown mycelium. Upward-pointing arrows indicate increases, downward pointing arrows indicate decreases, = indicates no change. 


\section{Exogenous addition of squalene}

upregulates the expression of $\mathrm{BcBOT}$ genes.

As indicated in Table 1, E20-pAN71 and E20-tri5.7 strains accumulated more squalene than the control strain T34-43b1.3. To determine if high levels of squalene would affect the expression of Botrytis virulence genes, this pathogen was grown in the presence of squalene at two different concentrations simulating the amount of this compound quantified in the mycelium of T34-43b1.3 $\left(0.6 \mu \mathrm{g} \mathrm{ml}^{-1}\right)$ and E20-pAN71 $\left(3 \mu \mathrm{g} \mathrm{ml}^{-1}\right)$. All the $B c B O T$ biosynthetic genes were upregulated by factors ranging from 3.063-fold $(P=0.013)$ for BcBOT3 to 6.586-fold $(P=$ $0.013)$ for $B c B O T 5$, when the highest squalene concentration was analyzed. The expression of these genes was significantly lower when $0.6 \mu \mathrm{g}$ of squalene per milliliter was used, raising relative expression values from 1.141 -fold $(P=0.501)$ for $B c B O T 1$ to 2.166 -fold $(P=0.049)$ for $B c B O T 5$. However, the other virulence genes analyzed showed a similar pattern of expression with both squalene concentrations. Thus, all those genes were upregulated at similar levels under both conditions, except sodl, which was not affected when grown on $0.6 \mu \mathrm{g}$ of squalene per milliliter but was upregulated at the higher squalene concentration (Fig. 7).

\section{Expression of tri5 gene in E20 slightly upregulated the expression of SA-related genes and downregulated or did not affect the expression of JA-related genes in tomato plants infected with $B$. cinerea.}

Tomato seeds were treated with E20-tri5.7 or the control strains E20-pAN71 and T34-43b1.3. Tomato plants were grown and inoculated with B05.10 as described below. Treatment with the Trichoderma strains studied in the present work did not significantly affect plant parameters such as stem length and diameter (data not shown). In addition, all the PDR genes analyzed were expressed at a lower level in plants infected with B05.10 and treated with either E20pAN71 or E20-tri5.7 than in the wild-type control strain T34$43 \mathrm{~b} 1.3$ (Fig. 8), indicating that ergl silencing has a negative effect on the ability of Trichoderma spp. to elicit a defense response in tomato plants. Expression of tri5 resulted in a very slight upregulation of SA-related genes with increases in the expression ratio of $1.169-(P=0.032)$ and 1.422 -fold $(P=0.032)$ for $P R 1 b 1$ and $P R-P 2$, respectively (Fig. 8D). Interestingly, the JA-related genes analyzed in the present work have a different behavior; while PINI was not affected by tri5 gene expression, PINII and TomLoxA were slightly but significantly downregulated by factors of $0.335-(P=$ $0.024)$ and 0.491 -fold $(P=0.032)$ in E20-tri5.7 compared with E20-pAN71 treated plants (Fig. 8D). In plants treated with these Trichoderma strains but not-infected with B05.10, a much lower expression level of SA-related genes was observed (Supplementary Fig. S4), indicating that the Botrytis infection strongly upregulated expression of those genes. Interestingly, in these comparisons, a downregulation of PINII was observed as a result of tri5 overexpression reaching a relative expression value of $0.136(P=0.033)$. This is a much lower level than that observed in plants inoculated with E20-pAN71 $(0.670[P=0.000])$.

Table 1. Quantification of squalene and ergosterol production by T34-43b1.3 (control), E20-pAN71, E20-tri5.7, and T34-SIL-E7

\begin{tabular}{|c|c|c|c|c|c|}
\hline \multirow[b]{2}{*}{ Strain } & \multirow[b]{2}{*}{ Dry weight (g) } & \multicolumn{2}{|c|}{ Squalene } & \multicolumn{2}{|c|}{ Ergosterol } \\
\hline & & $\mathbf{m g S} / g \mathrm{DW}^{\mathbf{y}}$ & $\%$ Variation & $\mathrm{mgE} / \mathrm{g} \mathrm{DW}$ & $\%$ Variation \\
\hline \multicolumn{6}{|c|}{ A. Samples from cultures grown in potato dextrose broth medium; $n=3$, analysis of variance } \\
\hline $\mathrm{T} 34-43 \mathrm{~b} 1.3$ & $0.184 \pm 0.005 \mathrm{a}$ & $0.099 \pm 0.000 \mathrm{a}$ & - & $6.086 \pm 0.104 \mathrm{a}$ & - \\
\hline E20-pAN71 & $0.178 \pm 0.008 \mathrm{a}$ & $0.212 \pm 0.032 \mathrm{c}$ & $+115.05 \%$ & $5.859 \pm 0.06 \mathrm{a}$ & - \\
\hline E20-tri5-7 & $0.203 \pm 0.022 \mathrm{a}$ & $0.174 \pm 0.039 \mathrm{~d}$ & $+75.65 \%$ & $4.73 \pm 0.21 b$ & $-22.28 \%$ \\
\hline T34-SIL-E7 & $0.125 \pm 0.024 b$ & $0.086 \pm 0.002 b$ & $-13.13 \%$ & $5.562 \pm 0.481 a$ & - \\
\hline \multicolumn{6}{|l|}{ At $96 \mathrm{~h}$} \\
\hline T34-43b1.3 & $0.292 \pm 0.01 \mathrm{a}$ & $0.096 \pm 0.043 a$ & - & $5.755 \pm 0.579 a$ & - \\
\hline E20-pAN71 & $0.269 \pm 0.01 b$ & $0.503 \pm 0.017 c$ & $+423.96 \%$ & $4.274 \pm 0.415 b$ & $-25.73 \%$ \\
\hline E20-tri5-7 & $0.278 \pm 0.004 c$ & $0.451 \pm 0.026 \mathrm{~d}$ & $+369.79 \%$ & $4.379 \pm 0.014 b$ & $-23.90 \%$ \\
\hline T34-SIL-E7 & $0.253 \pm 0.026 \mathrm{~b}, \mathrm{c}$ & $0.034 \pm 0.014 b$ & $-64.58 \%$ & $2.518 \pm 0.044 c$ & $-56.24 \%$ \\
\hline \multicolumn{6}{|c|}{ B. Samples from tomato hydroponic cultures grown in MS; $n=2$} \\
\hline $\mathrm{T} 34-43 \mathrm{~b} 1.3$ & $0.127 \pm 0.003 \mathrm{a}$ & $0.067 \pm 0.003 \mathrm{a}$ & - & $4.072 \pm 0.123 \mathrm{a}$ & - \\
\hline E20-pAN71 & $0.189 \pm 0.006 \mathrm{~b}$ & $0.378 \pm 0.024 \mathrm{c}$ & $+464.17 \%$ & $2.901 \pm 0.108 b$ & $-28.75 \%$ \\
\hline E20-tri5-7 & $0.198 \pm 0.007 b$ & $0.495 \pm 0.056 \mathrm{~d}$ & $+638.80 \%$ & $3.316 \pm 0.188 \mathrm{c}$ & $-18.56 \%$ \\
\hline T34-SIL-E7 & $0.142 \pm 0.001 \mathrm{c}$ & $0.053 \pm 0.005 b$ & $-20.89 \%$ & $3.331 \pm 0.201 \mathrm{c}$ & $-18.19 \%$ \\
\hline
\end{tabular}

${ }^{\mathrm{x}}$ Variation of produced squalene and ergosterol between the control and transformant strains. For each time point, values followed by different letters are significantly different $(P<0.05)$.

${ }^{\mathrm{y}}$ Measured in milligrams of squalene per gram of dry weight.

${ }^{\mathrm{z}}$ Measured in milligrams of ergosterol per gram of dry weight.

Table 2. Quantification of squalene and ergosterol production by T34-43b1.3 (control), Myrothecium roridum, Botrytis cinerea, and Fusarium sporotrichioides strains ${ }^{\mathrm{x}}$

\begin{tabular}{|c|c|c|c|c|c|}
\hline \multirow[b]{2}{*}{ Strain } & \multirow[b]{2}{*}{ Dry weight (g) } & \multicolumn{2}{|c|}{ Squalene } & \multirow{2}{*}{$\begin{array}{c}\text { Ergosterol } \\
\mathrm{mgE} / \mathrm{g} \mathrm{DW}^{\mathrm{z}}\end{array}$} & \multirow[b]{2}{*}{$\%$ Variation } \\
\hline & & $\mathbf{m g S / g ~ D W y}$ & $\%$ Variation & & \\
\hline T34-43b1.3 & $0.292 \pm 0.01 b$ & $0.096 \pm 0.043 \mathrm{~d}$ & & $5.755 \pm 0.579 b$ & \\
\hline$M$. roridum & $0.161 \pm 0.019 a$ & $0.043 \pm 0.002 b$ & $-55.20 \%$ & $4.143 \pm 0.246 a$ & $-27.71 \%$ \\
\hline B. cinerea & $0.493 \pm 0.009 c$ & $0.071 \pm 0.004 c$ & $-26.04 \%$ & $3.926 \pm 0.089 a$ & $-31.78 \%$ \\
\hline F. sportrichioides & $0.153 \pm 0.005 a$ & $0.030 \pm 0.002 \mathrm{a}$ & $-68.75 \%$ & $6.707 \pm 0.019 b$ & $+16.54 \%$ \\
\hline
\end{tabular}

${ }^{\mathrm{x}}$ From 96-h cultures grown in potato dextrose broth medium; $\%$ variation of produced squalene and ergosterol compared with the control are given; $n=2$, analysis of variance. Values followed by different letters are significantly different $(P<0.05)$.

y Milligrams of squalene per gram of dry weight.

z Milligrams of ergosterol per gram of dry weight. 
A

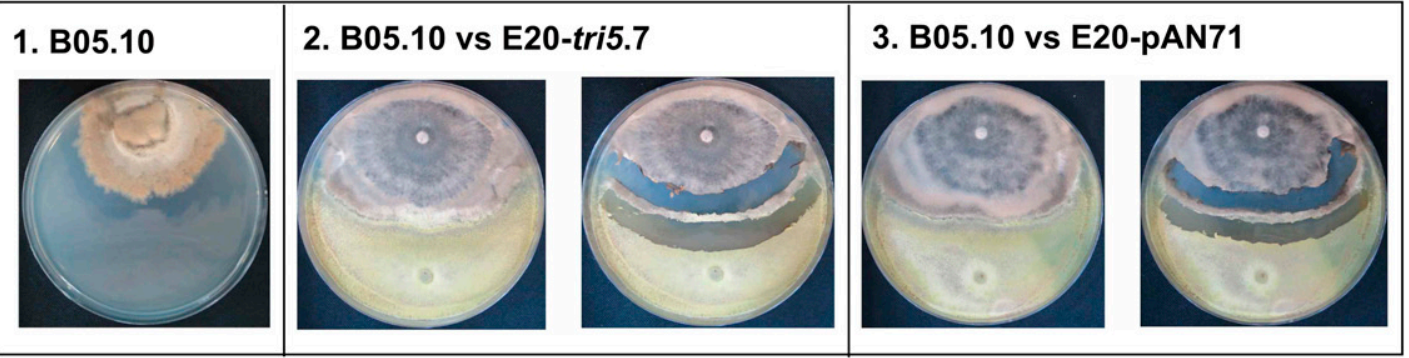

B

B05.10+E20-tri5.7 vs B05.10+E20-pAN71

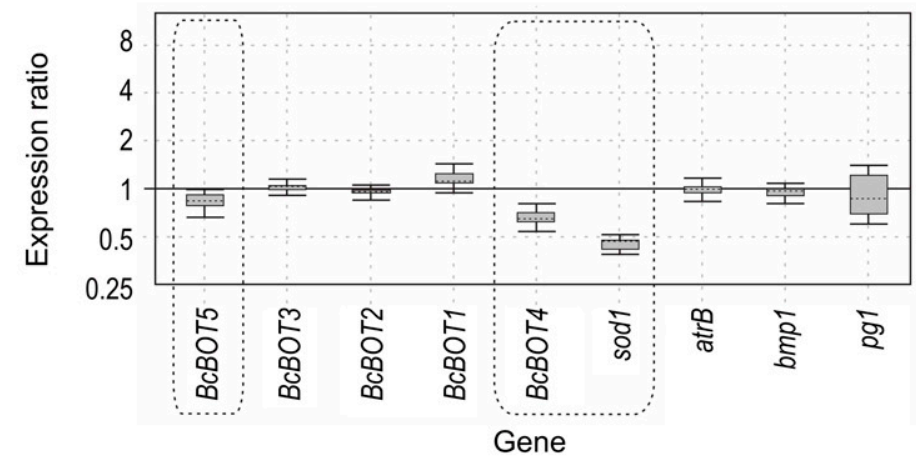

\begin{tabular}{|l|l|l|}
\cline { 2 - 3 } \multicolumn{1}{c|}{} & $\begin{array}{c}\text { Expression } \\
\text { ratio }\end{array}$ & $\boldsymbol{p}(\boldsymbol{H 1})$ \\
\hline BcBOT5 & $0.818^{*}$ & 0.000 \\
BcBOT3 & 1.006 & 0.872 \\
BcBOT2 & 0.937 & 0.253 \\
BcBOT1 & 1.119 & 0.235 \\
BcBOT4 & $0.645^{*}$ & 0.000 \\
sod1 & $0.429^{*}$ & 0.000 \\
atrB & 0.947 & 0.591 \\
bmp1 & 0.927 & 0.292 \\
pg1 & 0.882 & 0.660 \\
\hline
\end{tabular}

C E20-tri5.7+B05.10 vs E20-pAN71+B05.10
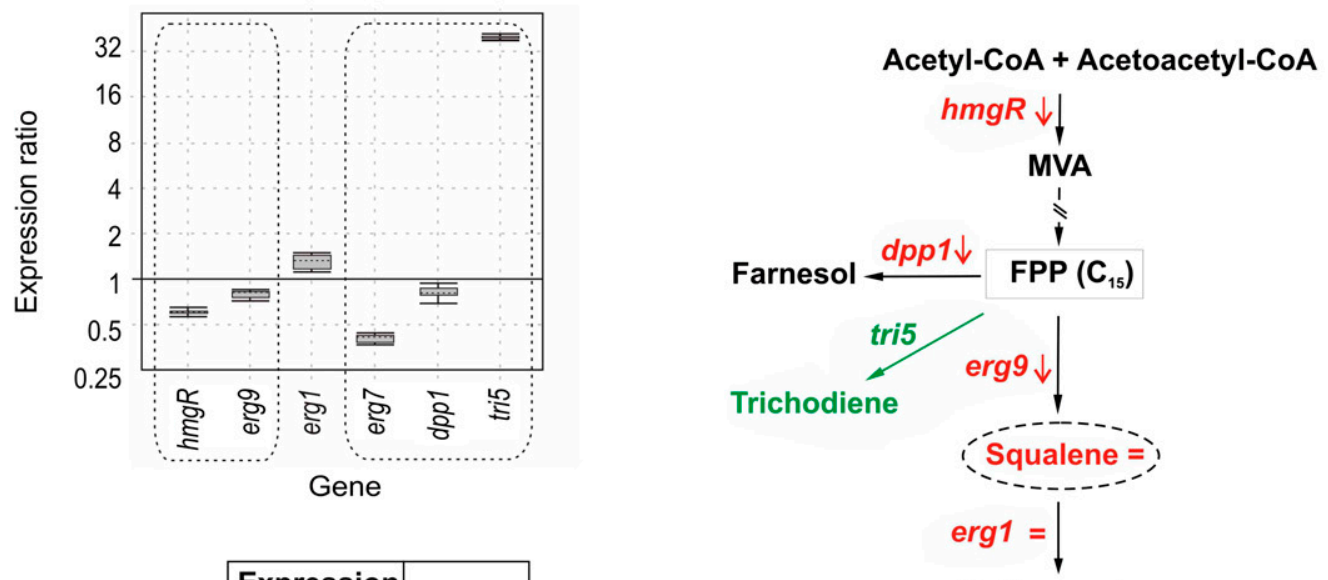

\begin{tabular}{|l|c|c|}
\cline { 2 - 3 } \multicolumn{1}{c|}{} & $\begin{array}{c}\text { Expression } \\
\text { ratio }\end{array}$ & $\boldsymbol{p}(\boldsymbol{H} 1)$ \\
\hline hmgR & $0.607^{*}$ & 0.000 \\
erg9 & $0.797^{*}$ & 0.000 \\
erg1 & 1.308 & 0.066 \\
erg7 & $0.407^{*}$ & 0.000 \\
dpp1 & $0.822^{*}$ & 0.000 \\
tri5 & $45.144^{*}$ & 0.036 \\
\hline
\end{tabular}

Oxidosqualene

$\operatorname{erg} 7 \downarrow \downarrow$

Lanosterol

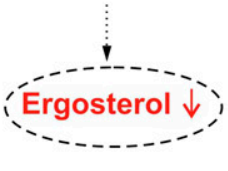

Fig. 5. A, The confrontation plates from which mycelia of B05.10 alone (1) or in confrontation with E20-tri5.7 (2) or E20-pAN71 (3) were collected to extract RNAs for comparative studies. B, Quantitative polymerase chain reaction (qPCR) analysis of the relative level of expression of several Botrytis virulence genes in mycelia confronted with E20-tri5.7 in comparison with the level of expression in mycelia of the pathogen confronted with the E20-pAN71 strain. C, Comparative expression levels of terpene-related genes in E20-tri5.7 and E20-pAN71, confronted in both cases with B05.10. Note that the order of the strains in $\mathrm{C}$ has been reversed with respect to B, since we are comparing the expression of genes between the Trichoderma strains, even though the confrontation plates used were the same as in B. Tables summarizing the qPCR data have been included in B and C. Boxes with dotted lines in B and C indicate genes with statistically significant differences. ${ }^{\#}$ Ta 37 was used to compare the level of expression of the tri5 gene in the E20-tri5.7 transformant, since tri5 is not present in strain E20. 
Silencing of $\operatorname{erg} 1$ and $\operatorname{erg} 7$ affect the colonization of tomato roots.

Roots of tomato hydroponic cultures were inoculated with T34-43b1.3 and the transformants E20-pAN71, E20-tri5.7, and T34-SIL-E7, as indicated below. Analysis by quantitative (q) PCR of the ratio of expression of Trichoderma $\alpha$-actin gene related to the level of expression of the tomato glyceraldehyde 3 -phosphate dehydrogenase gene resulted in ratios of colonization of 1.90, 0.81, and 0.26 for E20-pAN71, E20-tri5.7, and T34-SIL-E7, respectively, using, as a reference, the value of 1 for the colonization ability of T34-43b1.3. This indicates that silencing erg 1 in T34, resulting in a remarkable increase in the level of squalene production, significantly increased the ability to colonize tomato roots, while the expression of tri5 in E20 strongly reduced this ability. In the case of the T34-SIL-E7 strain, showing a lower level of ergosterol and squalene production than the wild-type strain, silencing of erg7 strongly reduced the tomato root colonization ability.

To investigate if these changes in the colonization ability correlate with the level of expression of PDR genes, expression of TomLoxA, which is involved in control of the spread of beneficial fungi in plant roots, was analyzed in tomato roots harvested from the same hydroponic cultures used to analyze the colonization ability. The relative expression values of this gene are in agreement with the data of colonization. TomLoxA was relatively upregulated by a factor of $3.569(P=0.018)$ in roots inoculated with E20-pAN71 versus roots inoculated with T34-43b1.3, while it was just slightly downregulated $(0.837$-fold; $P=0.000)$ with E20tri5.7 and not significantly affected (0.777-fold; $P=0.369)$ with T34-SIL-E7 (Fig. 9). Interestingly, expression of the other JA-related genes studied in the present work, PINI and $P I N I I$, was not detected from these samples, even with cDNA concentrations up to $256 \mathrm{ng} / \mu \mathrm{l}$.
The expression of $P R 1 b 1$ and $P R-P 2$, related to the salicylate pathway, were upregulated by factors of $1.376(P=0.000)$ and $1.498(P=0.000)$, respectively, when comparing E20-pAN71 versus T34-43b1.3 inoculated roots and were downregulated by factors of $0.245(P=0.000)$ and $0.282(P=0.000)$ when comparing E20-tri5.7 vs. T34-43b1.3 inoculated roots (Fig. 9). The expression of these two SA-related genes in roots inoculated with T34-SIL-E7 followed a drastically different pattern. $P R 1 b 1$ was strongly upregulated by a factor of 46.705 $(P=0.000)$ and $P R-P 2$ was not affected.

\section{Exogenous addition of squalene shows a concentration- dependent effect on regulation of the expression of tomato defense-related genes.}

Tomato plants grown in the presence of $0.6 \mu \mathrm{g}$ of squalene per milliliter, an amount similar to that produced by T3443b1.3, had high levels of expression of tomato PDR genes belonging to the SA pathway and little effect on PINI, PINII, or TomLoxA. However, when $3 \mu \mathrm{g}$ of squalene per milliliter was added to the medium, similar to that produced by the E20pAN71, PR-P2, PINI, and TomLoxA were not affected, PRIbI was upregulated, and PINII was downregulated. When the expression levels of these genes was compared between plants grown with $3 \mu \mathrm{g}$ of squalene per milliliter versus those grown in $0.6 \mu \mathrm{g}$ of squalene per milliliter, all these genes were relatively downregulated except TomLoxA, with a stronger downregulation effect over the SA-related genes, indicating that squalene might play a role as an elicitor of tomato plant defense response (Fig. 10B and C). However, this role is concentrationdependent in such a way that low concentrations strongly upregulate expression of SA-related genes and do not affect the expression of JA-related genes, while higher concentrations strongly downregulate the expression of $P R 1 b 1, P R-P 2$, and PINII when compared with the low concentration (Fig. 10).
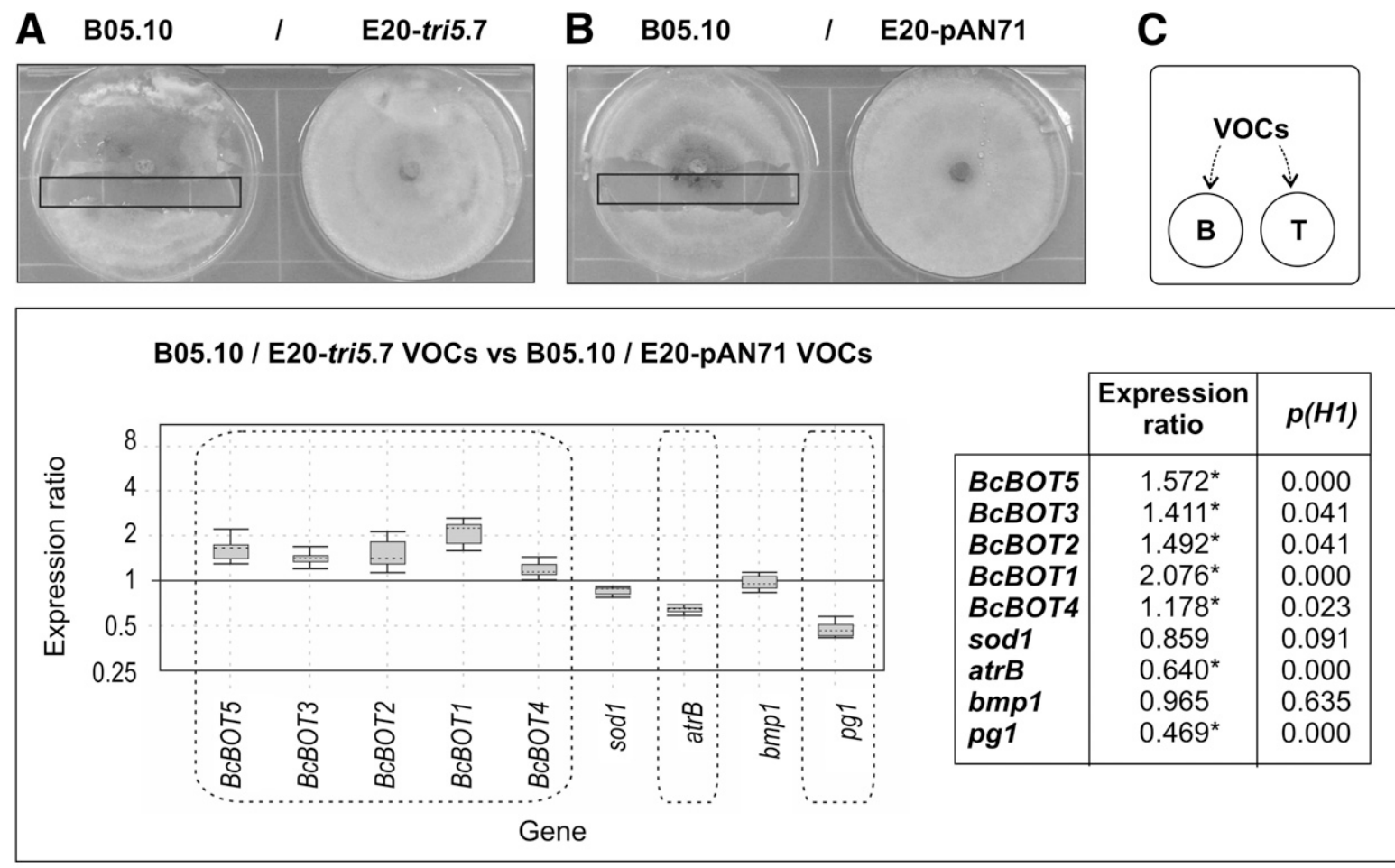

Fig. 6. Sets of cultures used in the interfungal assay of volatile compounds (VOC) produced by A, E20-tri5.7 and B, E20-pAN71. C, A scheme of the square plates used to perform this assay. Lower panels show quantitative polymerase chain reaction (qPCR) analysis of the relative level of expression of nine B. cinerea virulence genes in mycelia grown under the effect of VOC produced by E20-tri5.7, compared with the level of expression of those genes in mycelia grown under the effect of E20-pAN71 VOC. The outlined boxes in the Botrytis plates illustrate the mycelium that was scraped for qPCR analysis. The relative gene expression values are included on the right. Boxes with dotted line: genes with statistically significant differences. 
Despite the differences observed in the expression of PDR genes, no significant phenotypic differences were observed among plants grown in the two squalene concentrations analyzed compared with control plants grown without squalene (Fig. 10A).

\section{Effect of squalene on the ability of T34-43b1.3 to elicit} in vivo expression of tomato defense-related genes.

Based on the data of exogenous addition of squalene on upregulation of tomato PDR genes, we wanted to determine if squalene may have some in vivo effect on the expression of PDR genes. An experiment was performed by growing tomato plants inoculated with T34-43b1.3 and watering with fertilizer supplemented with $3 \mu \mathrm{g}$ of squalene per milliliter, and, for a control, plants inoculated with the same Trichoderma strain but just watered with fertilizer without squalene and supplemented with the same amount of acetone used to dilute the squalene.

After 4 weeks of growth, the qPCR results showed that squalene addition at a concentration similar to that produced by
E20-pAN71 downregulated the expression of all the tomato PDR genes tested in comparison with plants not supplemented with squalene (Fig. 11).

\section{DISCUSSION}

Trichoderma species fill a variety of environmental niches and include those that have been evaluated extensively as biocontrol agents (Harman et al. 2004; Monte 2001). Trichoderma strains can produce extracellular enzymes and antibiotics but also may compete with fungal pathogens for space and nutrients (Howell 2003). When trying to dissect out the particular factors that are critical in the development of a successful biocontrol agent, one must consider the interaction of the fungus being considered as the biocontrol agent, the antagonistic phytopathogen, and the host plant. In this paper, we have narrowed the parameters to include $T$. harzianum, a fungus that has been studied as a biocontrol agent (Harman et al. 2004; Hermosa et al. 2013; Lorito et al. 2010), Botrytis cinerea, a fungus known to cause plant disease (Choquer et al. 2007;

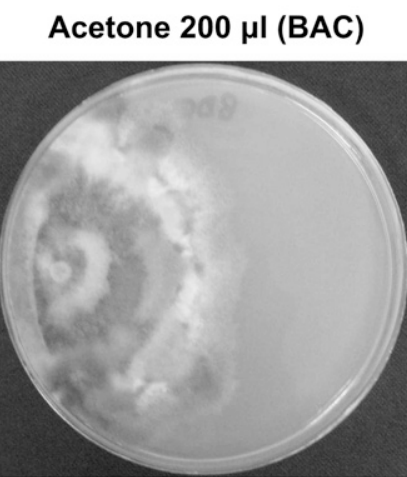

BS1 vs BAC

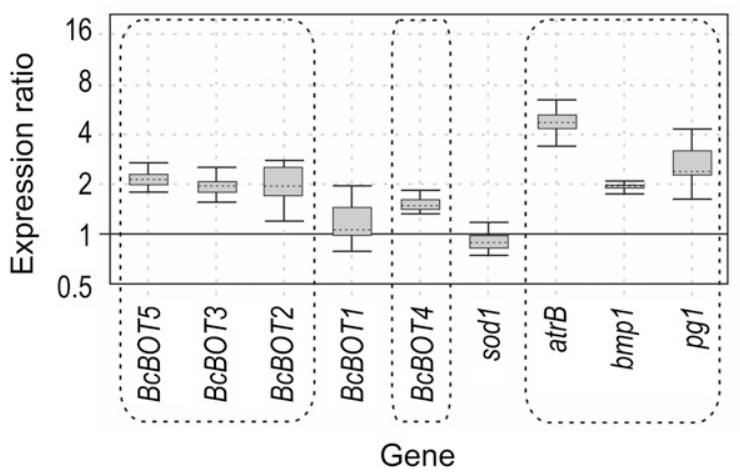

\begin{tabular}{|l|c|c|}
\cline { 2 - 3 } \multicolumn{1}{c|}{} & $\begin{array}{c}\text { Expression } \\
\text { ratio }\end{array}$ & $\boldsymbol{p}(\boldsymbol{H} 1)$ \\
\hline BcBOT5 & $2.166^{*}$ & 0.049 \\
BcBOT3 & $1.949^{*}$ & 0.000 \\
BcBOT2 & $1.828^{*}$ & 0.000 \\
BcBOT1 & 1.141 & 0.501 \\
BcBOT4 & $1.514^{*}$ & 0.000 \\
sod1 & 0.895 & 0.219 \\
atrB & $4.576^{*}$ & 0.000 \\
bmp1 & $1.897^{*}$ & 0.000 \\
pg1 & $2.589^{*}$ & 0.000 \\
\hline
\end{tabular}
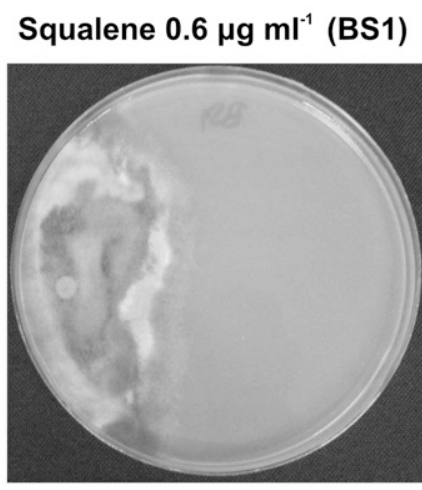

Squalene $3 \mu \mathrm{g} \mathrm{ml}^{-1}$ (BS2)

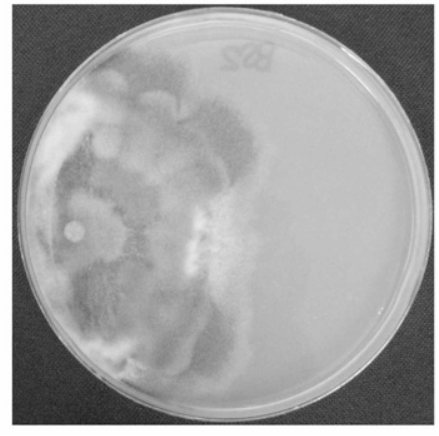

BS2 vs BAC

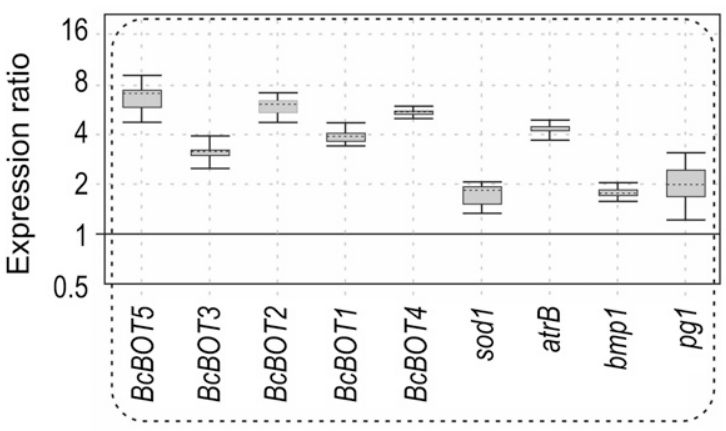

Gene

\begin{tabular}{|l|c|c|}
\cline { 2 - 3 } \multicolumn{1}{c|}{} & $\begin{array}{c}\text { Expression } \\
\text { ratio }\end{array}$ & $\boldsymbol{p}(\boldsymbol{H} 1)$ \\
\hline BcBOT5 & $6.586^{*}$ & 0.013 \\
BcBOT3 & $3.063^{*}$ & 0.013 \\
BcBOT2 & $5.772^{*}$ & 0.036 \\
BcBOT1 & $3.780^{*}$ & 0.013 \\
BcBOT4 & $5.285^{*}$ & 0.013 \\
sod1 & $1.713^{*}$ & 0.000 \\
atrB & $4.158^{*}$ & 0.013 \\
bmp1 & $1.746^{*}$ & 0.042 \\
pg1 & $1.914^{*}$ & 0.013 \\
\hline
\end{tabular}

Fig. 7. Quantitative polymerase chain reaction analysis of the relative level of expression of nine $B$. cinerea virulence genes in mycelia grown in the presence of 0.6 or $3 \mu \mathrm{g}$ of squalene per milliliter (BS1 and BS2, respectively), in comparison with the level of expression in mycelia grown without squalene (BAC). Boxes with dotted lines indicate genes with statistically significant differences. 
Williamson et al. 2007), and Solanum lycopersicum, a plant susceptible to $B$. cinerea.

Previous studies have shown that Trichoderma spp. produce trichothecenes, most notably trichodermin and HA. To determine if trichothecenes, well-described mycotoxins (Desjardins 2006; Masuda et al. 2007; McCormick et al. 2011), are important in fighting off fungal antagonists, we have systematically been studying the impact of HA, produced by $T$. arundinaceum, on biocontrol activity, using tomato plants as a host (Malmierca et al. 2012, 2013, 2015a). When trichothecene genes involved in the biosynthetic pathway of HA have been either silenced or deleted, we have seen reduced antifungal activity against $B$. cinerea and also a reduction in the expression of tomato PDR genes associated with the SA and JA pathways, indicating that HA plays an important function in the sensitization of Trichoderma-pretreated plants (Malmierca et al. 2012). Further continuation of these studies to determine if a particular precursor to HA had an effect on gene expression in $B$. cinerea or plant defense showed that VOC, including TD, which is a precursor to HA, upregulates expression of tomato PDR genes suggesting that VOC act as signaling mechanisms in the interaction of Trichoderma spp. with plants (Malmierca et al. 2015b).

Terpene compounds are involved in the biocontrol process due to their antifungal properties but, additionally, some, such as ergosterol, are involved in the structure of cell membranes. Silencing of ergl in T. harzianum led to transformants with lower levels of ergosterol and an increase in the level of expression of $\operatorname{erg} 7$ (which follows $\operatorname{erg} 1$ in the biosynthetic pathway of ergosterol) (Cardoza et al. 2006b). The trichothecene biosynthetic pathway and the sterol biosynthetic pathway both draw from FPP, which serves as a common precursor. In the present work, the use of strain E20, a transformant of $T$. harzianum T34 silenced in the ergl gene (Cardoza et al. 2006b), allowed us to study the effect of TD (product of Tri5 activity) and squalene (substrate for $\operatorname{erg} 1$ ).

When ergl is silenced (strain E20), the accumulation of squalene increases dramatically $(400+\%)$ yet the amount of ergosterol decreases only slightly from the levels detected in T34 ( erg $1^{+}$tri $5^{-}$). Since totally silencing ergl would be lethal, the small amount of squalene being made must be enough to form the levels of ergosterol measured. Expression of tri5 in E20 ( $\mathrm{erg} 1-\mathrm{si}$ tri $\left.5^{+}\right)$resulted in a slight reduction $(10 \%)$ in the level of squalene and little change in the level of ergosterol when measured from 96-h PDB-grown mycelia, which can be explained as a result of the FPP channeling toward TD by Tri5, thereby reducing levels of squalene. Unexpectedly, silencing of erg7 resulted in a remarkable reduction in levels of squalene and ergosterol accumulation, as the levels of ergosterol produced in 96-h PDB-grown mycelia were much lower than those observed in the $\operatorname{erg} 1$-silenced transformant. This indicates that mutations at different sites in the ergosterol biosynthetic pathway differ in how they affect the level of production of

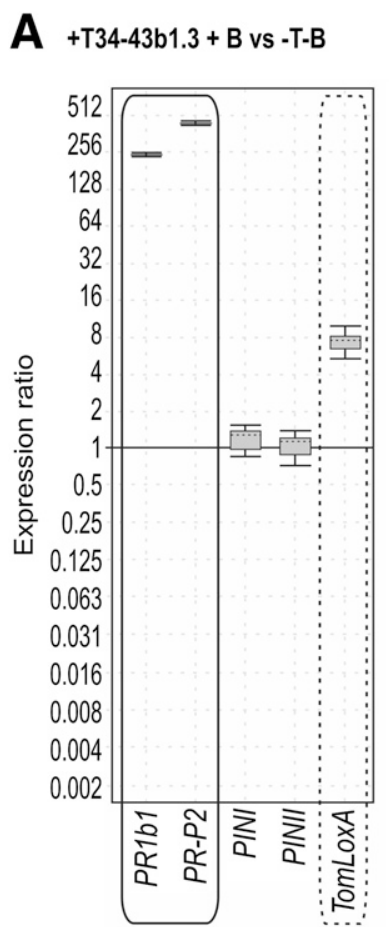

Gene

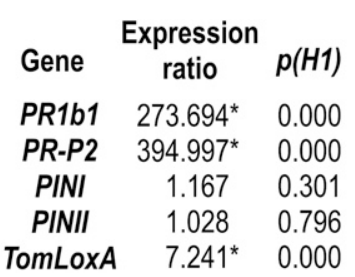

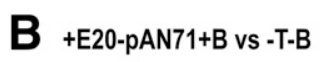

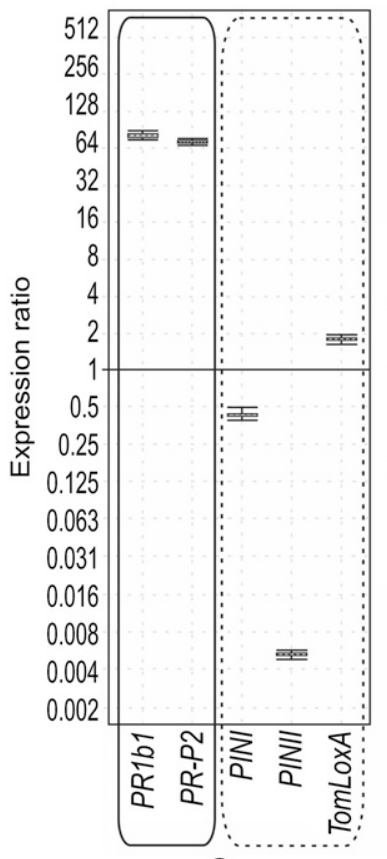

Gene

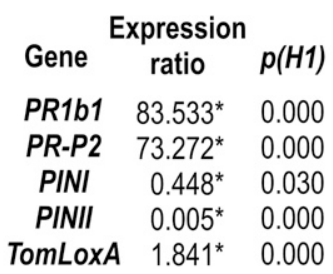

C

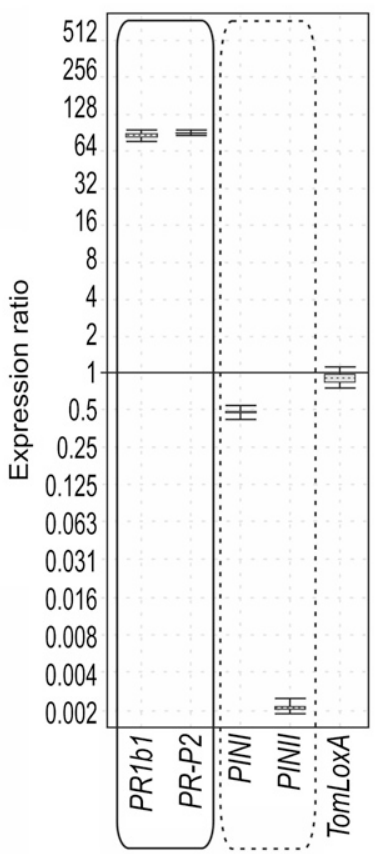

Gene

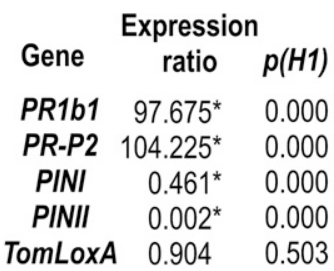

D +E20-tri5.7+B vs E20-pAN71+B

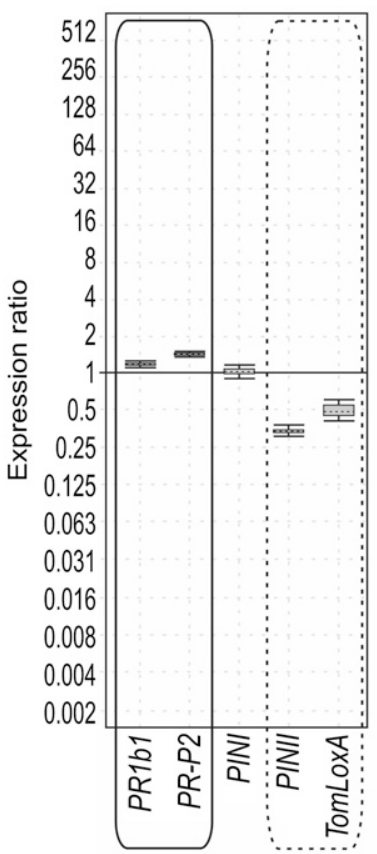

Gene

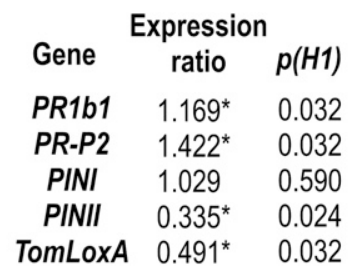

Fig. 8. Quantitative polymerase chain reaction analysis of the relative level of expression of five tomato defense-related genes in leaves collected from tomato plants whose seeds were coated with conidia of A, T34-43b1.3, B, E20-pAN71, or C, E20-tri5.7 and were then infected with spores of B05.10 (+B), in comparison with the level of expression of these genes in plants not inoculated nor infected (-T-B). D, Relative expression level in plants treated with E20-tri5.7 $+B$, in comparison with plants treated with E20-pAN71+B. Boxes with solid lines indicate salicylic acid-related genes with statistically significant differences; boxes with dotted lines indicate jasmonate-related genes with statistically significant differences. 
this compound. The modifications in the levels of squalene and ergosterol production observed in mycelia detached from roots of tomato hydroponic cultures suggest that, in this interaction, the tomato roots alter the production and accumulation of ergosterol and squalene in T. harzianum. This may be due to a recognition-like mechanism that would make root colonization by these strains possible. This hypothesis is in agreement with the previously reported role of ergosterol as a general elicitor recognized by plants as a microbe-associated molecular pattern in the fungal-plant interaction (Klemptner et al. 2014; Nürnberger et al. 2004). Ergosterol would specifically induce the plant defense responses by being linked to a specific plant receptor (Amborabé et al. 2003; Rossard et al. 2006; Kauss and Jeblick 1996). Thus, this reduction in the level of ergosterol would drive a reduction in the intensity of plant defense responses leading to an easier colonization of the plant.

The expression of tri5 upregulated the expression of the terpene genes $h m g R$, ergl, and erg7 in PDB-grown cultures, while the quantity of squalene was slightly reduced, the quantity of ergosterol was not. If, indeed, TD is channeling FPP away from the sterol biosynthetic pathway, one might expect the level of expression of all the genes analyzed to be increased. Since erg9 expression does not appear to be increased by the presence of tri5 activity, it suggests that there are other factors regulating the expression of the genes involved in ergosterol biosynthesis. Although the presence of squalene epoxidase activity is necessary for TRB resistance, the slight increase in ergl gene expression by the presence of tri5 TD, is enough to provide some additional resistance to TRB. Once again, tri5 gene expression, by siphoning off FPP and reducing squalene levels, may induce ergl expression. However, when the level of expression of these genes was analyzed in confrontation experiments against $\mathrm{B} 05.10$, the presence of tri5 slightly repressed the expression levels of all terpene genes analyzed except ergl, which indicates that the interaction with the pathogen B05.10 drives the repression of pathways involved in fungal growth, e.g., the ergosterol biosynthetic pathway. This implies the existence of a balance between fungal growth and self defense in Trichoderma spp. when challenged with a pathogen, resulting in channeling the flux of precursors toward one or the other function, depending on the environmental conditions.

VOC produced by $T$. harzianum are known to affect aerial and root growth as well as gene expression, increasing lateral root growth of tomato seedlings (Malmierca et al. 2015b). The expression of tri5 in T34 had a negative effect on the lateral root growth induced by T34 alone (Malmierca et al. 2015b). The research presented here showed that tri5 expression in E20 also reduces lateral root and aerial growth in tomatoes, when compared with the effects of E20 alone. When the tomato PDR genes were analyzed, the VOC produced by E20-tri5 dramatically upregulated all the genes analyzed, especially the SArelated genes, which saw relative levels as high as 1,559-fold. These induction values were much higher than those observed by the VOC produced by T34-tri5 (Malmierca et al. 2015b), suggesting that the higher levels of TD produced by E20-tri5 may have been responsible. These results show that TD elicits the expression of tomato PDR genes, which is in agreement with the effect of other VOC released by Trichoderma spp. (Naznin et al. 2014; Vinale et al. 2008).

No remarkable effect was observed on the expression of B05.10 virulence genes by the production of TD when analyzed
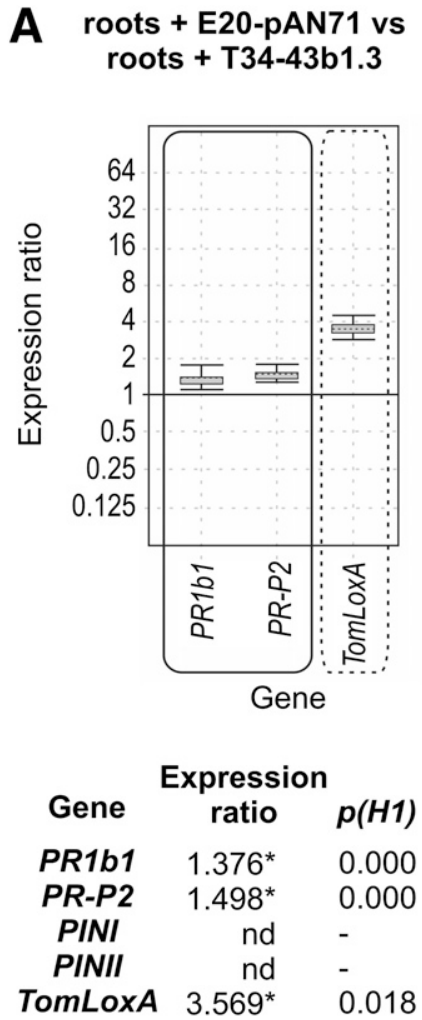

B roots + E20-tri5.7 vs roots + T34-43b1.3
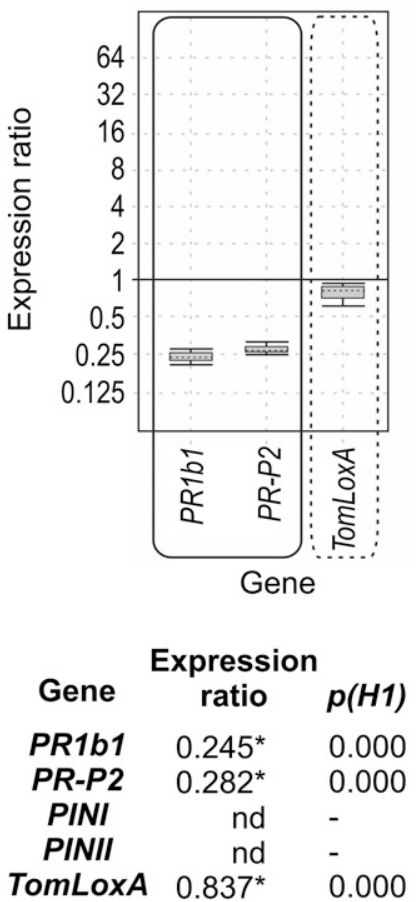
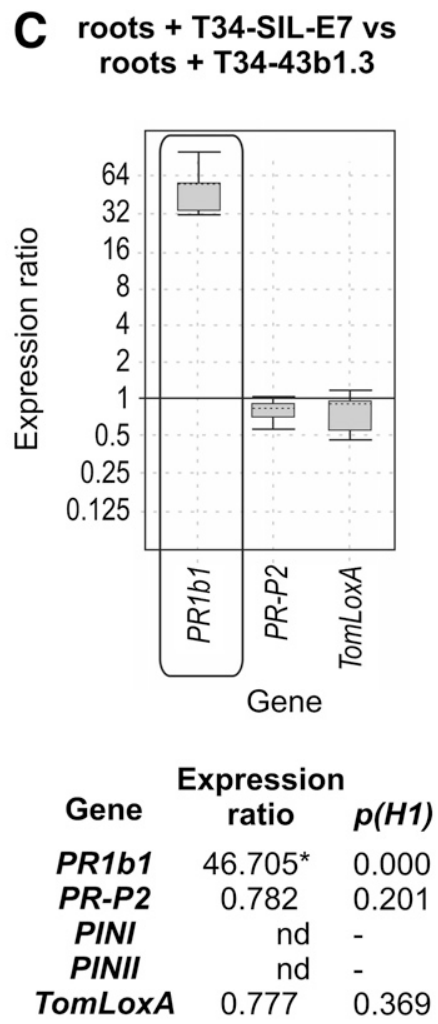

Fig. 9. Quantitative polymerase chain reaction analysis of the relative level of expression of $P R 1 b 1, P R-P 2$, and TomLoxA genes in roots harvested from tomato hydroponic cultures inoculated with A, E20-pAN71, B, E20-tri5.7, and C, T34-SIL-E7, in comparison with the level of expression of these genes in roots inoculated with T34-43b1.3. The lower part of the figure includes the numeric relative gene expression levels corresponding to the graphic illustrated above. Boxes with solid lines indicate salicylic acid-related genes with statistically significant differences; boxes with dotted lines indicate TomLoxA (a jasmonaterelated gene) with statistically significant differences. Note that expression of PINI and PINII genes was not detected (nd) in the experimental conditions used in the present study. 
in confrontation experiments, which contrasted with the slight induction of $B C B O T$ genes observed when tri5 was expressed in the wild-type strain (Malmierca et al. 2015b). However, the effect of VOC produced by E20-tri5.7 in a VOC assay did show a slight but significant induction of $B C B O T$ genes. This result indicates that an in vitro effect of TD may show slight variations in upregulation over the in vivo effect of TD or that strain E20 ( erg1-si tri5 $5^{-}$carries one or more other factors that override the effect caused by TD. Based on the results indicated above, we focused our attention on the level of squalene, which is much higher in E20-pAN71 and E20-tri5.7 than in T34. The possible involvement of the increased amount of squalene on the level of expression of $B C B O T$ genes was investigated. When B05.10 was grown in the presence of exogenous squalene (at a level similar to that produced by E20), induction of all the $B c B O T$ genes occurred at a remarkably higher level than that observed when a small amount of squalene (similar to the level produced by T34-43b1.3) was used. This confirms our hypothesis that the effect of silencing ergl prevails over the effect of TD production in the induction of Botrytis virulence genes, especially those involved in the BOT biosynthetic pathway. The role of squalene in the integrity of cell membranes has been previously characterized in yeast (Spanova et al. 2012). However, its involvement in the regulation of fungal interactions has not been described. Our results indicate that squalene, in addition to its role as a key intermediate in ergosterol biosynthesis, also acts as an important elicitor in fungal interactions. The role of ergosterol as an elicitor of defense response in plants has been
A

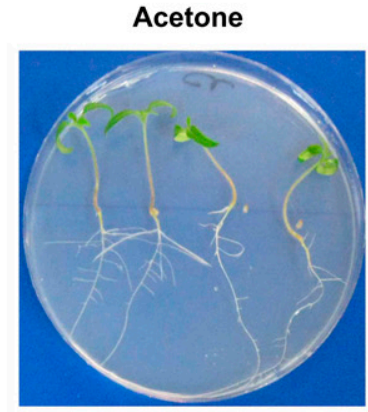

B

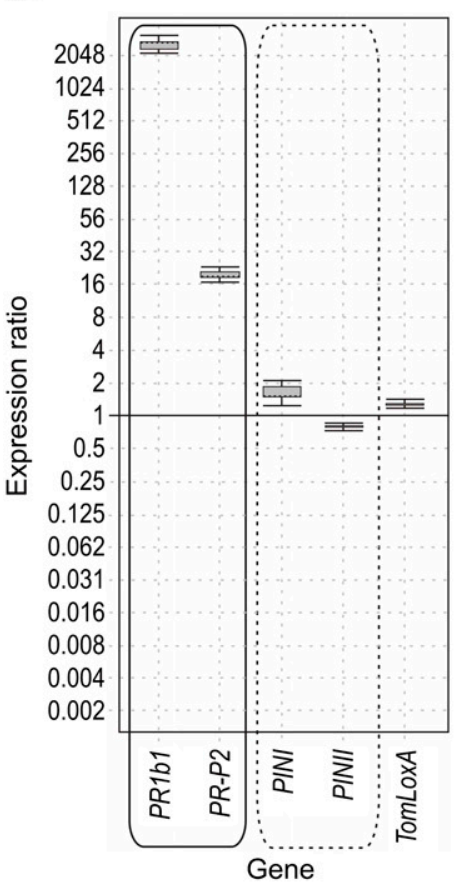

C

\begin{tabular}{|c|c|c|}
\hline Gene & $\begin{array}{l}\text { Expression } \\
\text { ratio }\end{array}$ & $p(H 1)$ \\
\hline$P$ & $2685.137^{*}$ & 0.000 \\
\hline$P$ & $19.928 *$ & 0.000 \\
\hline$P I N$ & $1.688^{*}$ & 0.000 \\
\hline PINII & $0.773^{*}$ & 0.034 \\
\hline TomLoxA & 1.261 & 0.061 \\
\hline
\end{tabular}

Squalene $0.6 \mu \mathrm{g} \mathrm{ml}^{-1}$ (TS1)

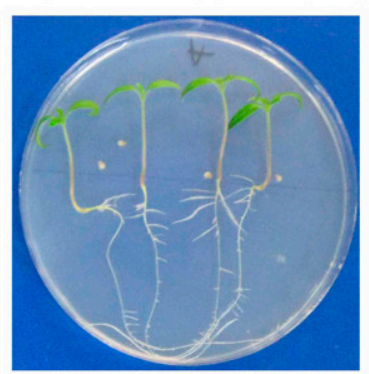

TS2 vs acetone
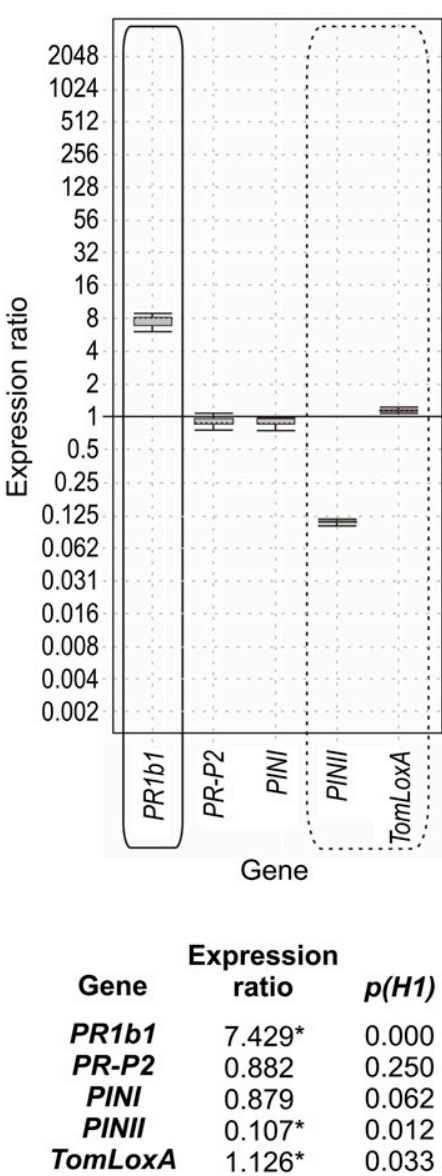

Squalene $3 \mu \mathrm{g} \mathrm{ml}^{-1}$ (TS2)

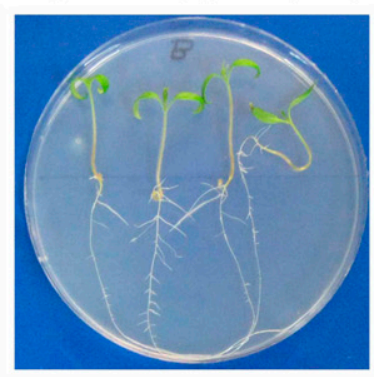

TS2 vs TS1

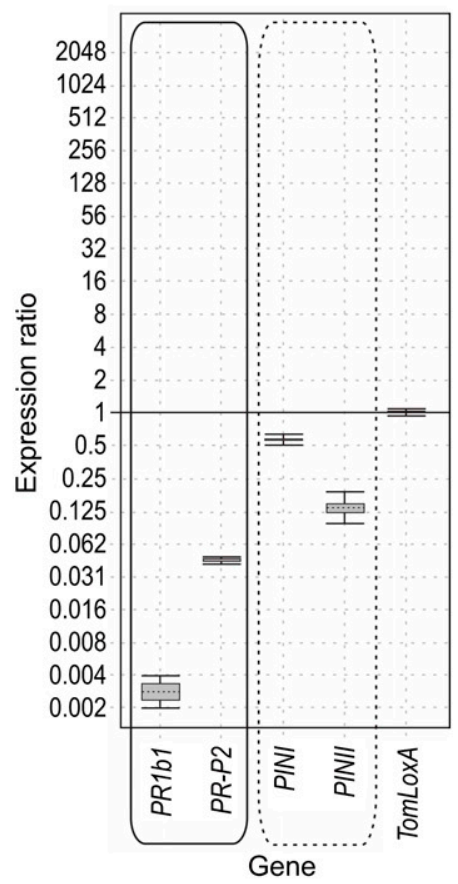

$\begin{array}{ccc}\text { Expression } & \begin{array}{c}\text { Expre } \\ \text { ratio }\end{array} & \boldsymbol{p}(\boldsymbol{H} 1) \\ \text { PR1b1 } & 0.003^{*} & 0.011 \\ \text { PR-P2 } & 0.044^{*} & 0.030 \\ \text { PINI } & 0.572^{*} & 0.030 \\ \text { PINII } & 0.066^{*} & 0.034 \\ \text { TomLoxA } & 1.027 & 0.438\end{array}$

Fig. 10. A, Control plants grown in the presence of acetone (TAC) and tomato plants grown in Murashige and Skoog medium supplemented with 0.6 or $3 \mu \mathrm{g}$ of squalene per milliliter (TS1 and TS2, respectively). B and C, Quantitative polymerase chain reaction analysis of the relative level of expression of five tomato defense-related genes from these plants. Boxes with solid lines indicate salicylic acid-related genes with statistically significant differences; boxes with dotted lines indicate jasmonate-related genes with statistically significant differences. 
reported (Rossard et al. 2006; 2010), but the studies presented in this manuscript also suggest that squalene can be important. It has been shown that the squalene to sterols ratio regulates the fluidity or rigidity in cellular membranes, with this balance being essential for membrane stability (Hauss et al. 2002; Spanova et al. 2012). The increase in the level of squalene production in ergl-si transformants (Table 1) in the presence or absence of tomato cultures supports the importance of this signal in membrane integrity, either for the fungus alone or in plant-fungal interactions.

Silencing of ergl and the consequent increase in the level of squalene production increased the ability of E20-pAN71 to colonize tomato roots compared with the control strain T34$43 \mathrm{~b} 1.3$, when studied with hydroponic cultures. These data correlated with the relative increase in the level of expression of TomLoxA when comparing the same root samples. TomLoxA has been related to the control of the spread of beneficial fungi in roots (Harel et al. 2014; León-Morcillo et al. 2012). Previous reports also indicate that SA plays an important role in preventing distribution of the fungus to the vascular system and its spread into aerial parts (Alonso-Ramírez et al. 2014). Thus, our results are in agreement with these previous data, since the analysis of hydroponic cultures of tomato plants treated with E20-pAN71 showed a slight increase in the level of expression of SA-related genes, which would help control the spread of this fungus to other parts of the plant. Furthermore, to support our hypothesis about the involvement of squalene in root colonization by Trichoderma spp., the transformant T34-SIL-E7, showing lower levels of squalene and ergosterol production, was used. A dramatic reduction in the ratio of tomato root colonization was observed compared with the three other strains. The observation that E20-pAN71, which has high levels of squalene, had almost twice the colonization ratio as did T34$43 \mathrm{~b} 1.3$ suggests that squalene and ergosterol levels have a critical role in root colonization and a modification of their levels affects this function. However, even though E20-tri5.7 had high levels of squalene, it only had one-half the ability to colonize roots as did E20-pAN71, suggesting that TD also plays a role in root colonization. Therefore, production of TD might stop the recognition of this transformant as a beneficial strain, reducing its ability to colonize tomato roots in comparison with E20-pAN71.

Infection of tomato seeds by T34-SIL-E7 resulted not only in a reduction in its colonization ability but in a strong upregulation of $P R 1 b 1$ in tomato roots. Thus, in addition to the regulation of fluidity and rigidity of cell membranes (Spanova et al. 2012), one or both the squalene level or the total sterols contents in fungal membranes might have a role in the regulation of fungal colonization of plant roots and, at the same time, in activating plant defense responses. Possibly, Trichoderma biocontrol strains have coevolved with plants to have a level of squalene or ergosterol in their membranes that makes possible i) root colonization and ii) maintenance of PDR genes, mainly those that are SA-related and expressed at a level that would allow the fungus to spread to distal parts of the plant (Alonso-Ramírez et al. 2014). T34-SIL-E7 must be recognized by tomato roots as a pathogen-like organism, resulting in high levels of expression of PRIb1 and a low level of root penetration. When production of squalene was quantified in the pathogens $M$. roridum, B. cinerea, and $F$. sporotrichioides, which produce the sesquiterpene toxins roridin, botrytidal, and $\mathrm{T}-2$ toxin, respectively, squalene production was reduced by $55.2,26.04$, and $68.75 \%$, respectively, compared with the level of squalene production in T34-43b1. This indicates that, in spite of their virulent properties, their low level of squalene production might be important in the perception of these fungi as pathogen organisms (Table 2). However, additional studies will be needed to further confirm this hypothesis.
To emphasize the role of squalene in plant-fungal interactions, tomato plants grown in the presence of exogenous squalene at a concentration similar to that produced by T34-43b1.3 $(0.6 \mu \mathrm{g}$ $\mathrm{ml}^{-1}$ ) showed that the SA-related genes were strongly upregulated, while the JA-related genes were just slightly affected, in comparison with control plants grown without squalene. All the genes except TomLoxA were relatively downregulated in plants grown with higher levels of squalene $\left(3 \mu \mathrm{g} \mathrm{ml}^{-1}\right)$, similar to those levels produced by E20, compared with plants grown with the lower squalene concentration. Suppression was also seen in plants inoculated with T34-43b1.3 ( $\left.\operatorname{ergl} 1^{+}\right)$and watered with $3 \mu \mathrm{g}$ $\mathrm{ml}^{-1}$ squalene, which again, supports the importance of this compound on the fungal-plant and fungal-fungal interactions. Surprisingly, in the study of the effect of VOC on plant response, while ergl-si (E20) downregulates PINI and PINII expression, E20-tri5.7 strongly upregulates all five genes measured, including PINI and PINII, suggesting that TD also affects PDR gene expression.

Adding other parameters may lead to changes in gene expression levels. The addition of $B$. cinerea VOC to growing tomatoes dramatically upregulated expression of SA-related genes (Malmierca et al. 2015b). For determination of the added effect of Trichoderma spp. on PDR gene expression, we looked at the effect of the addition of both Trichoderma spp. and $B$. cinerea on plant growth and gene expression. Together, B05.10 and T34-43b1.3 ( $\left.\operatorname{rgl}^{+}\right)$increased expression of the SA-related genes and one of the JA/ET pathway genes, while ergl-si transformants did not have as great an induction effect. The presence of Tri5 increased the erg1-si effect slightly.

In conclusion, TD by itself has an elicitor function on the expression of tomato PDR genes and Botrytis virulence genes. However, this elicitor activity can be overridden by other physiological conditions. In addition to the previously reported effect of ergosterol in eliciting plant defense, we propose the involvement of squalene in that process, which indicates that the balance of squalene and ergosterol is important for maintaining cellular membrane stability as well as playing a critical role in the interactions with plants and other fungi in the

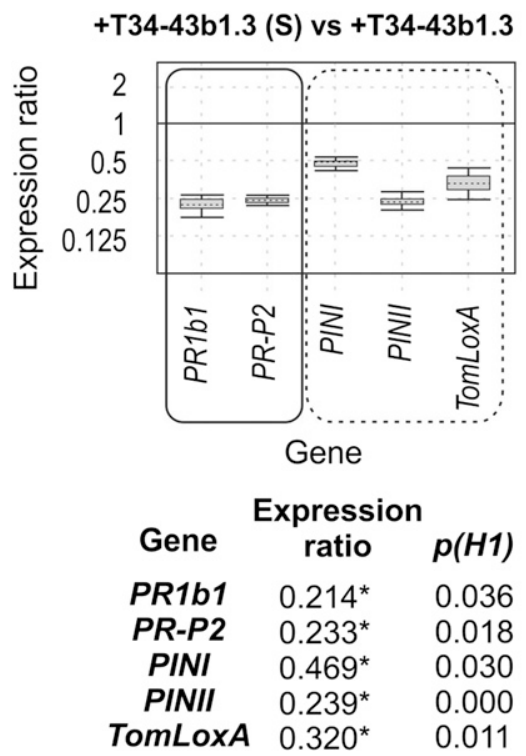

Fig. 11. Quantitative polymerase chain reaction analysis of cDNAs from tomato plants inoculated with T34-43b1.3 that were watered with the regular fertilizer supplemented with $3 \mu \mathrm{g}$ of squalene per milliliter (S) versus plants inoculated with T34-43b1.3 and watered without squalene, to determine the effect of this intermediate in the expression of tomato defense-related genes. Box with solid lines indicates salicylic acid-related genes with statistically significant differences; box with dotted lines indicates jasmonate-related genes with statistically significant differences. 
regulation of defense and virulence mechanisms. These data also emphasize the importance of cell stability and integrity in the fungal interactions as well as in the biocontrol activity of Trichoderma spp.

Continued studies using isogenic strains with a single gene silenced or deleted at a time will contribute to a better understanding of the very complex interaction between the biocontrol agent, the antagonist, and the host plant.

\section{MATERIALS AND METHODS}

\section{Strains and culture conditions.}

Trichoderma arundinaceum IBT 40837 (Ta37), a producer of the trichothecene HA was used as the source of tri5. Trichoderma harzianum CECT 2413 (T34), a well-characterized biocontrol strain and a trichothecene nonproducer, was the parent strain of transformant T. harzianum E20 (E20) in which erg1 has been silenced (Cardoza et al. 2006b). E20 was used as the recipient of Ta37 tri5 to obtain transformant E20-tri5.7. T34-SIL-E7 is a transformant of strain T34 with the erg7 gene silenced following the same strategy used to silence expression of ergl and was used for comparative purposes in the tomato root colonization assays. Strain T34-43b1.3, a transformant of the T34 strain with the empty pJL43b1 plasmid (Cardoza et al. 2006a), and strain E20-pAN71, a transformant of E20 with the empty pAN71 plasmid (Punt et al. 1987), were used as reference strains.

Botrytis cinerea B05.10 (B05.10) is a BOT-producing phytopathogenic strain that was used in confrontation and plant assays. Myrothecium roridum ATCC 52485 and Fusarium sporotrichioides CECT 20166 are two phytopathogenic fungi that produce the sesquiterpene toxins roridin and T-2 toxin, respectively, and were used together with B05.10 for squalene and ergosterol quantification.

Solanum lycopersicum var. Marmande was used to determine the effect of ergl silencing, tri5 gene expression, and squalene addition on the regulation of tomato PDR genes as well as the effect of TD on root architecture (in VOC assays).

Trichoderma strains were grown on plates of PPG medium (2\% mashed potatoes [Nestlé, Barcelona, Spain], 2\% glucose [Panreac Applichem, Barcelona, Spain], 2\% agar [Becton Dichinson, Heidelberg, Germany]) and were incubated at $28^{\circ} \mathrm{C}$ for 4 to 7 days to sporulate; for confrontation studies, agar plugs of $7 \mathrm{~mm}$ diameter were taken from these plates. B. cinerea, $M$. roridum, and $F$. sporotrichioides were grown by cultivation on plates of MEA medium (2\% glucose [Panreac Applichem, Barcelona, Spain], 2\% malt extract [Panreac Applichem], 1\% peptone [Becton Dickinson, Heidelberg, Germany], 2\% agar [Becton Dichinson], $\mathrm{pH}$ 5.6) and were incubated at $21^{\circ} \mathrm{C}$ for 7 days with a photoperiod of $16 \mathrm{~h}$ of light and $8 \mathrm{~h}$ of dark. For sporulation, B05.10 was cultivated on tomato juice agar medium (Oxoid LTD, Hampshire, U.K.) and was incubated as indicated above.

\section{Nucleic acid extraction and manipulation.}

Procedures for fungal genomic DNA isolation and for Southern hybridization were performed as described previously (Cardoza et al. 2011). Isolation of total RNA from Trichoderma spp., Botrytis cinerea, and tomato roots and aerial parts was performed as described by Malmierca and coworkers (2015b).

The cDNAs were synthesized from $1 \mu \mathrm{g}$ of total RNA and a reverse transcription system based on the use of an oligo(dT) $)_{15}$ as primer (Promega, Madison, WI, U.S.A.). cDNAs were quantified using a Nanodrop 2000 (Thermo Scientific, Wilmington, DE, U.S.A.).

Labeling, hybridization, and immunological detection were carried out with a nonradioactive labeling and immunological detection kit with CDP-Star as the chemiluminescent substrate
(Roche, Mannheim, Germany), as previously described (Cardoza et al. 2007).

\section{Transformation of T. harzianum E20 and selection of the transformants.}

Transformation of $T$. harzianum E20 protoplasts with pANT5-F plasmid containing the tri5 gene-expression cassette or with the control pAN71 plasmid was carried out as described previously (Cardoza et al. 2006a), using the resistance to hygromycin as a selection marker. Plasmid pANT5-F, containing the tri5 gene under the control of the gpdA gene promoter of Aspergillus nidulans was constructed as described previously (Malmierca et al. 2015b).

\section{Quantification of ergosterol and squalene and resistance to TRB.}

Total intracellular sterols were extracted from mycelia grown after 24 or $96 \mathrm{~h}$ of growth on PDB medium or from Trichoderma-tomato hydroponic cultures performed as indicated below. Ergosterol and squalene content were calculated as reported previously (Cardoza et al. 2007; Ghimire et al. 2009). All measurements were made in triplicate. Ergosterol and squalene was also quantified in duplicate from mycelium detached from tomato roots grown in hydroponic cultures. For the quantification of ergosterol and squalene in supernatants collected from these hydroponic cultures, $10 \mathrm{ml}$ of MS broth collected after the plant-fungal incubation period were lyophylized and resuspended in $3 \mathrm{ml}$ of $25 \% \mathrm{KOH}$ dissolved in $\mathrm{H}_{2} \mathrm{O} /$ ethanol (35:65) solution, and then, were extracted and quantified as indicated above.

Assays of TRB resistance were carried out as described previously (Malmierca et al. 2015b), using concentrations of $0.1,1$, and $2.5 \mu \mathrm{g}$ of TRB per milliliter (Lamisil 250; Novartis, Basel, Switzerland) in Trichoderma minimal medium (Penttilä et al. 1987).

\section{Statistical analysis.}

Analysis of variance and Kruskal-Wallis tests were performed with IBM SSPS Statistics 19 software and were used to compare the data regarding production of squalene and ergosterol between the strains analyzed in the present work.

\section{Confrontation assays between $T$. harzianum and B05.10.}

Confrontation assays were started from spores of T. harzianum strains grown for 5 days on PPG at $28^{\circ} \mathrm{C}$ and B05.10 grown for 7 days on MEA at $21^{\circ} \mathrm{C}$ with a photoperiod of $16 \mathrm{~h}$ of light and $8 \mathrm{~h}$ of dark. A 7-mm-diameter agar plug with growing mycelia of $B$. cinerea was placed on one side of a $150-\mathrm{mm}$ petri dish containing $50 \mathrm{ml}$ of MEA medium with a cellophane membrane ( 25 to $30 \mathrm{kDa}$ cutoff) placed on its surface and was incubated at $21^{\circ} \mathrm{C}$ with a photoperiod of $16 \mathrm{~h}$ of light and $8 \mathrm{~h}$ of dark. After 4 days of $B$. cinerea growth (colony diameter approximately $40 \mathrm{~mm}$ ), a 7-mm-diameter agar plug of $T$. harzianum was placed on the surface, at the opposite side from the $B$. cinerea plug. The confrontation plates were incubated at $28^{\circ} \mathrm{C}$ for 7 days in the dark. Fungi usually began to interact 4 days after the addition of the Trichoderma plug. Samples of mycelium were scraped from the 'interaction' regions to extract RNA for qPCR analysis.

\section{Effect of exogenous squalene on Botrytis gene expression.}

To determine the effect of squalene on the expression of B05.10 virulence genes, MEA plates containing 0.6 or $3 \mu \mathrm{g}$ of squalene per milliliter (Sigma, St. Louis), in both cases diluted in a total of $300 \mu \mathrm{l}$ of acetone that was used as solvent, were overlaid with a cellophane sheet and were inoculated with a 7-mm-diameter plug from a 7-day-old culture of B05.10. A plate including $300 \mu \mathrm{l}$ 
of acetone was used as a control. The plates were then incubated for 4 days at $21^{\circ} \mathrm{C}$, with a photoperiod of $16 \mathrm{~h}$ of light and $8 \mathrm{~h}$ of dark followed by 7 more days at $28^{\circ} \mathrm{C}$ in the dark. Mycelia were collected and were used to extract RNA for qPCR analysis.

\section{qPCR experiments.}

In order to perform comparative studies of gene expression, previously described oligonucleotides of $B$. cinerea virulence genes, tomato PDR genes, and Trichoderma terpene and tri5 genes were used (Cardoza et al. 2011; Malmierca et al. 2012, 2015a; Pinedo et al. 2008; Tucci et al. 2011). According to GeNorm software (Vandesompele et al. 2002) results, $\alpha$-actin and gpd were used as references to analyze expression of Trichoderma genes. The $\alpha$-actin gene was used as a housekeeping gene for tomato PDR gene expression assays and the $E F 1 b$ gene was used as a housekeeping gene for $B$. cinerea virulence gene analysis in confrontation assays. The qPCR reactions were carried out using the system Step One Plus (Applied Biosystems, Foster City, CA, U.S.A.). The reactions were performed in a total volume of $20 \mu \mathrm{l}$, adding the following components for reaction: $10 \mu \mathrm{l}$ of Power SYBR Green PCR master mix (Applied Biosystems), $0.4 \mu \mathrm{l}$ of Forward Primer $10 \mu \mathrm{M}, 0.4 \mu \mathrm{l}$ of Reverse Primer $10 \mu \mathrm{M}, 5 \mu \mathrm{l}$ of cDNA, and $\mathrm{H}_{2} \mathrm{O}$ to $20 \mu \mathrm{l}$. Relative expression values and the significance of the differences between the gene expression levels were calculated using REST 2009 software (Pfaffl et al. 2002). For each primer pair used in this work, we performed a standard curve with $320,160,80,40,20$, and $10 \mathrm{ng}$ of cDNA for Trichoderma and Botrytis genes or 160, 80, 40, 20, 10 , and $5 \mathrm{ng}$ of cDNA for tomato genes to determine the PCR amplification efficiency (E value). Each measurement was made in triplicate, using cDNA pooled from three biological replications.

To quantify the tomato-root colonization ability of the T34 transformants studied in the present work and compare it to that of the T34-43b1.3 control strain, oligonucleotides of the tomato $G A P D H$ and $T$. harzianum $\alpha$-actin genes were used (Cardoza et al. 2014; Tucci et al. 2011). The amount of cDNA from Trichoderma spp. in the tomato roots was quantified by qPCR comparison of the level of Trichoderma $\alpha$-actin relative to the level of tomato GAPDH in each sample. Once the qPCR was performed, the cycles to threshold values $(\mathrm{Ct})$ were converted to nanograms of cDNA by using two calibration curves representing the $\mathrm{Ct}$ values for known (tomato or T34) cDNA concentrations. Using this approach, the ratio of tomato-root colonization for the T34-43b1.3 strain was assigned the value of 1 and the values for the E20-pAN71, E20-tri5.7, and T34SIL-E7 transformants were compared with it by simple mathematical calculations.

\section{Chemical analysis of TD.}

Conidia from the different Trichoderma strains were inoculated into YEPD broth $(0.1 \%$ Bacto yeast extract [Difco, Detroit], $0.1 \%$ Bacto peptone [Difco], and 5\% glucose [Sigma]) and were grown at $28^{\circ} \mathrm{C}$ and $200 \mathrm{rpm}$ for 8 days in a New Brunswick Innova 44 shaker incubator (New Brunswick Scientific Co., Enfield, CT, U.S.A.). Cultures were extracted with ethyl acetate and the extracts were analyzed with gas chromatography-mass spectrometry (GC-MS) as described previously (Malmierca et al. 2012) and were quantified using a standard curve.

\section{Capture of VOC from headspace of E20-tri5.7 solid cultures.}

Columns and procedures used to trap VOC from E20-tri5.7 cultures were performed as described previously (Malmierca et al. 2015b; Tholl et al. 2006). VOC were eluted from the traps with $300 \mu$ lof hexane and were analyzed with GC-MS as indicated above.
Assay of the effect Trichoderma VOC on plant defense gene expression, plant architecture, and on $B$. cinerea gene expression.

The effect of VOC on tomato plants was studied following procedures previously described (Fiers et al. 2013; Malmierca et al. 2015b). After the incubation period, plants were photographed to observe differences in the aerial parts and also in the main and secondary root length. RNAs were extracted from the aerial parts of the plants selected from the different volatile treatments and cDNAs were analyzed by qPCR to determine the effect of volatiles on expression of several tomato genes involved in defense response: $P R 1 b 1$ and $P R-P 2$ genes related to salicylate-mediated responses and induced by SA; PINI and PINII genes, induced through the JA signal transduction pathway, and TomLoxA, encoding an enzyme of the lipoxygenase family, which is involved in JA response and defense (Malmierca et al. 2012; Tucci et al. 2011).

In order to analyze the effect of Trichoderma VOC on $B$. cinerea gene expression, a similar procedure to that used to study the effect of Trichoderma VOC on tomato plants was used. MEA plates overlaid with a cellophane sheet were inoculated with a plug extracted from B05.10 or Trichoderma 7-day-old cultures. Then, these two plates were incubated together inside square plates containing $300 \mathrm{ml}$ of MS medium, which were sealed to avoid the release of VOC (Supplementary Fig. S5). The square plates were incubated for 6 days at $21^{\circ} \mathrm{C}$ with a photoperiod of $16 \mathrm{~h}$ of light and $8 \mathrm{~h}$ of dark, to allow fungal growth and the subsequent action of Trichoderma VOC on B05.10. After this incubation period, mycelia from B05.10 plates were immediately scraped to extract RNA for qPCR analysis.

\section{Assays on tomato plants.}

Surface-sterilized tomato seeds were planted in commercial loamy field soil (Kekkilä 50/50 [Projar S.A.,Valencia, Spain] Malmierca et al. [2012] describe composition). For Trichoderma treatments, seeds were coated with an aqueous suspension containing $2 \times 10^{8}$ conidia per milliliter and were air dried before planting. Pots with untreated tomato seeds were used as controls. The pots were incubated in a greenhouse with a photoperiod of $16 \mathrm{~h}$ of light and $8 \mathrm{~h}$ of dark at $21 \pm 2^{\circ} \mathrm{C}$ and were watered with fertilizer as needed. Measurements of stem height, stem diameter, and main root length were taken after 4 weeks.

Four-week-old plants obtained from tomato seeds coated with T34-43b1.3 (control), E20-pAN71 (control), and the tri5expressing transformant were inoculated with $15 \mu \mathrm{l}$ of $B$. cinerea conidial suspensions $\left(1 \times 10^{6}\right.$ spores $\left.\mathrm{ml}^{-1}\right)$ in germination buffer

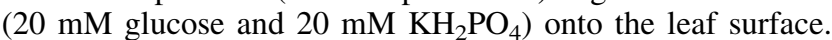
Inoculated plants were incubated in a humid chamber $(50 \%$ humidity) under the conditions (temperature and photoperiod) described above. Two inoculations were made per leaf on four leaves per plant for 16 plants per treatment, with two replicates for each experiment. After 4 days, the necrotic lesions were measured. Leaves before and after pathogen inoculation were collected to extract RNA as described above. In parallel, uninoculated plants were used as control.

In order to determine the in vivo effect of the exogenous addition of squalene, a set of tomato plants was grown from seeds coated with T34-43b1.3 and, then, were grown as described above and watered with the usual fertilizer supplemented with $3 \mu \mathrm{g}$ of squalene per milliliter, diluted in acetone. Another set of plants inoculated with T34-43b1.3 watered with the same volume of fertilizer supplemented with acetone was used as a control.

Tomato-Trichoderma hydroponic cultures were carried out as previously described (Rubio et al. 2012). First, sterile tomato seeds were placed inside phytatray II boxes (Sigma) (30 seeds per box) on a sterile gauze sheet over a sterile stainless-steel 
screen, which held them $1 \mathrm{~cm}$ above $100 \mathrm{ml}$ of MS medium (Duchefa, Haarlem, The Netherlands) and were maintained at $21 \pm 2{ }^{\circ} \mathrm{C}$ in a plant growth chamber with controlled light and humidity conditions, as described above, for 2 weeks. Spores of Trichoderma spp. ( $10^{7}$ spores) were used to inoculate $250-\mathrm{ml}$ flasks containing $100 \mathrm{ml}$ of PDB medium. Each strain was cultured at $28^{\circ} \mathrm{C}$ and $250 \mathrm{rpm}$ in darkness for $48 \mathrm{~h}$. Mycelia were harvested by filtration, were washed with sterile water, and were used to inoculate phytatray II boxes that contained 2-week-old tomato plants. Tomato-Trichoderma hydroponic cultures were maintained at $25^{\circ} \mathrm{C}$ and $80 \mathrm{rpm}$ for $20 \mathrm{~h}$. Finally, Trichoderma mycelia attached to roots were recovered with a direct cold-water jet and were used for squalene and ergosterol quantification, and the cleaned roots were used for the analysis by qPCR of the Trichoderma colonization rate.

Tomato in vitro cultures were performed in $150-\mathrm{mm}$ petri dishes to determine the effect of two concentrations of squalene on the expression of PDR genes. The squalene concentrations and the volumes used were the same as those described above to determine the effect of exogenous squalene on Botrytis gene expression. Plants grown as described previously (Malmierca et al. 2015a) were collected and the aerial parts were used for tomato gene expression analysis by qPCR.

\section{ACKNOWLEDGMENTS}

We thank J. Álvarez from the University of León and J. Teresi from the Bacterial Foodborne Pathogens and Mycology Unit of the United States Department of Agriculture Agricultural Research Service for their excellent technical assistance. This research was supported by grants from MICINN and MINECO (AGL2009-13431-C02, AGL2012-40041-C02-01, and AGL2012-40041-C02-02) and from Junta de Castilla y León (LE125A122). M. Gómez was granted a FPU fellowship by the Spanish Ministry of Science and Innovation (AP2007-02835).

\section{LITERATURE CITED}

Alonso-Ramírez, A., Poveda, J., Martín, I., Hermosa, R., Monte, E., and Nicolás, C. 2014. Salicylic acid prevents Trichoderma harzianum from entering the vascular system of roots. Mol. Plant Pathol. 15:823-831.

Amborabé, B. E., Rossard, S., Pérault, J. M., and Roblin, G. 2003. Specific perception of ergosterol by plant cells. C. R. Biol. 326:363-370.

Asadollahi, M. A., Maury, J., Schalk, M., Clark, A., and Nielsen, J. 2010. Enhancement of farnesyl diphosphate pool as direct precursor of sesquiterpenes through metabolic engineering of the mevalonate pathway in Saccharomyces cerevisiae. Biotechnol. Bioeng. 106:86-96.

Cano, P. M., Seeboth, J., Meurens, F., Cognie, J., Abrami, R., Oswald, I. P., and Guzylack-Piriou, L. 2013. Deoxynivalenol as a new factor in the persistence of intestinal inflammatory diseases: An emerging hypothesis through possible modulation of Th17-mediated response. PLoS One 8:e53647.

Cardoza, R. E., Hermosa, M. R., Vizcaíno, J. A., González, F., Llobell, A., Monte, E., and Gutiérrez, S. 2007. Partial silencing of a hydroxymethylglutaryl-CoA reductase-encoding gene in Trichoderma harzianum CECT 2413 results in a lower level of resistance to lovastatin and lower antifungal activity. Fungal Genet. Biol. 44:269-283.

Cardoza, R. E., Malmierca, M. G., and Gutiérrez, S. 2014. Overexpression of erg1 gene in Trichoderma harzianum CECT 2413: Effect on the induction of tomato defence-related genes. J. Appl. Microbiol. 117: 812-823.

Cardoza, R. E., Malmierca, M. G., Hermosa, M. R., Alexander, N. J., McCormick, S. P., Proctor, R. H., Tijerino, A. M., Rumbero, A., Monte, E. and Gutiérrez, S. 2011. Identification of loci and functional characterization of trichothecene biosynthesis genes in filamentous fungi of the genus Trichoderma. Appl. Environ. Microbiol. 77:4867-4877.

Cardoza, R. E., Vizcaíno, J. A., Hermosa, M. R., Monte, E., and Gutiérrez S. 2006a. A comparison of the phenotypic and genetic stability of recombinant Trichoderma spp. generated by protoplast- and Agrobacteriummediated transformation. J. Microbiol. 44:383-395.

Cardoza, R. E., Vizcaíno, J. A., Hermosa, M. R., Sousa, S., González, F. J., Llobell, A., Monte, E., and Gutiérrez, S. 2006b. Cloning and characterization of the ergl gene of Trichoderma harzianum: Effect of the $\operatorname{erg} 1$ silencing on ergosterol biosynthesis and resistance to terbinafine. Fungal Genet. Biol. 43:164-178.
Chandra, S., Heinstein, P. F., and Low, P. S. 1996. Activation of phospholipase A by plant defense elicitors. Plant Physiol. 110:979-986.

Chapman, K. D. 1998. Phospholipase activity during plant growth and development and in response to environmental stress. Trends Plant Sci. 3:419-426.

Choquer, M., Fournier, E., Kunz, C., Levis, C., Pradier, J. M., Simon, A., and Viaud, M. 2007. Botrytis cinerea virulence factors: New insights into a necrotrophic and polyphageous pathogen. FEMS (Fed. Eur. Microbiol. Soc.) Microbiol. Lett. 277:1-10.

Cole, R. A., Jarvis, B. B., and Schweikert, M. A. 2003. Handbook of Secondary Metabolites. Academic Press, New York.

Degenkolb, T., Dieckmann, R., Nielsen, K. F., Gräfenhan, T., Theis, C., Zafari, D., Chaverri, P., Isamaiel, A., Brückner, H., von Döhren, H., Thrane, U., Petrine, O., and Samuels, G. J. 2008. The Trichoderma brevicompactum clade: A separate lineage with new species, new peptabiotics, and mycotoxins. Mycol. Prog. 7:177-219.

Desjardins, A. E. 2006. Fusarium Mycotoxins: Chemistry, Genetics, and Biology. The American Phytopathological Society, St. Paul, MN, U.S.A.

Dixon, R. A., and Lamb, C. J. 1990. Molecular communication in interactions between plants and microbial pathogens. Annu. Rev. Plant Physiol. Plant Mol. Biol. 41:339-367.

Fiers, M., Lognay, G., Fauconnier, M.-L., and Jijakli, M. H. 2013. Volatile compound-mediated interactions between barley and pathogenic fungi in the soil. PLoS One 8:e66805

Gershenzon, J., and Dudareva, N. 2007. The function of terpene natural products in the natural world. Nat. Chem. Biol. 3:408-414.

Ghimire, G. P., Lee, H. C., and Sohng, J. K. 2009. Improved squalene production via modulation of the methylerythritol 4-phosphate pathway and heterologous expression of genes from Streptomyces peucetius ATCC 27952 in Escherichia coli. Appl. Environ. Microbiol. 75:7291-7293.

Gomès, E., Sagot, E., Gaillard, C., Laquitaine, L., Poinssot, B., Sanejouand, Y. H., Delrot, S., and Coutos-Thévenot, P. 2003. Nonspecific lipidtransfer protein genes expression in grape (Vitis sp.) cells in response to fungal elicitor treatments. Mol. Plant Microbe Interact. 16:456-464.

Harel, Y. M., Mehari, Z. H., Rav-David, D., and Elad, Y. 2014. Systemic resistance to gray mold induced in tomato by benzothiadiazole and Trichoderma harzianum T39. Phytopathology 104:150-157.

Harman, G. E., Howell, C. R., Viterbo, A., Chet, I., and Lorito, M. 2004 Trichoderma species-opportunistic, avirulent plant symbionts. Nat. Rev. Microbiol 2:43-56.

Hauss, T., Dante, S., Dencher, N. A., and Haines, T. H. 2002. Squalane is in the midplane of the lipid bilayer: Implications for its function as a proton permeability barrier. Biochim. Biophys. Acta 1556:149-154.

Hermosa, R., Rubio, M. B., Cardoza, R. E., Nicolás, C., Monte, E., and Gutiérrez, S. 2013. The contribution of Trichoderma to balancing the costs of plant growth and defense. Int. Microbiol. 16:69-80.

Hohn, T. M., and Beremand, P. D. 1989. Isolation and nucleotide sequence of a sesquiterpene cyclase gene from the trichothecene-producing fungus Fusarium sporotrichioides. Gene 79:131-138.

Howell, C. R. 2003. Mechanisms employed by Trichoderma species in the biological control of plant diseases: The history and evolution of current concepts. Plant Dis. 87:4-10.

Kauss, H., and Jeblick, W. 1996. Influence of salicylic acid on the induction of competence for $\mathrm{H}_{2} \mathrm{O}_{2}$ elicitation: Comparison of ergosterol with other elicitiors. Plant Physiol. 111:755-763.

Klemptner, R. L., Sherwood, J. S., Tugizimana, F., Dubery, I. A., and Piater, L. A. 2014. Ergosterol, an orphan fungal microbe-associated molecular pattern (MAMP). Mol. Plant Pathol. 15:747-761.

Lee, S., Suh, S., Kim, S., Crain, R. C., Kwak, J. M., Nam, H.-G., and Lee, Y. 1997. Systemic elevation of phosphatidic acid and lysophospholipid levels in wounded plants. Plant J. 12:547-556.

León-Morcillo, R. J., Angel, J., Martín-Rodríguez, Vierheilig, H., Ocampo, J. A., and García-Garrido, J. M. 2012. Late activation of the 9-oxylipin pathway during arbuscular mycorrhiza formation in tomato and its regulation by jasmonate signalling. J. Exp. Bot. 63:3545-3558.

Lorito, M., Woo, S. L., Harman, G. E., and Monte, E. 2010. Translational research on Trichoderma: From 'omics to the field. Annu. Rev. Phytopathol. 48:395-417.

Malmierca, M. G., Barua, J., McCormick, S. P., Izquierdo-Bueno, I., Cardoza, R. E., Alexander, N. J., Hermosa, R., Collado, I. G., Monte, E., and Gutiérrez, S. 2015a. Novel aspinolide production by Trichoderma arundinaceum with a potential role in Botrytis cinerea antagonistic activity and plant defence priming. Environ. Microbiol. 17: 1103-1118.

Malmierca, M. G., Cardoza, R. E., Alexander, N. J., McCormick, S. P., Collado, I. G., Hermosa, R., Monte, E., and Gutiérrez, S. 2013 Relevance of trichothecenes in fungal physiology: Disruption of tri5 in Trichoderma arundinaceum. Fungal Genet. Biol. 53:22-33. 
Malmierca, M. G., Cardoza, R. E., Alexander, N. J., McCormick, S. P. Hermosa, R., Monte, E., and Gutiérrez, S. 2012. Involvement of Trichoderma trichothecenes in the biocontrol activity and induction of plant defense-related genes. Appl. Environ. Microbiol. 78:4856-4868.

Malmierca, M. G., McCormick, S. P., Cardoza, R. E., Alexander, N. J., Monte, E., and Gutiérrez, S. 2015b. Production of trichodiene by Trichoderma harzianum alters the perception of this biocontrol strain by plants and antagonized fungi. Environ. Microbiol. 17:2628-2646.

Masuda, D., Ishida, M., Yamaguchi, K., Yamaguchi, I., Kimura, M., and Nishiuchi, T. 2007. Phytotoxic effects of trichothecenes on the growth and morphology of Arabidopsis thaliana. J. Exp. Bot. 58:1617-1626.

McCormick, S. P., Stanley, A. M., Stover, N. A., and Alexander, N. J. 2011. Trichothecenes: From simple to complex mycotoxins. Toxins (Basel) 3: 802-814.

Monte, E. 2001.Understanding Trichoderma: Between agricultural biotechnology and microbial ecology. Int. Microbiol. 4:1-4.

Naznin, H. A., Kiyohara, D., Kimura, M., Miyazawa, M., Shimizu, M., and Hyakumachi, M. 2014. Systemic resistance induced by volatile organic compounds emitted by plant growth-promoting fungi in Arabidopsis thaliana. PLoS One 9:e86882

Nielsen, K. F., Gräfenhan, T., Zafari, D., and Thrane, U. 2005. Trichothecene production by Trichoderma brevicompactum. J. Agric. Food Chem. 53: 8190-8196.

Nürnberger, T., Brunner, F., Kemmerling, B., and Piater, L. 2004. Innate immunity in plants and animals: Striking similarities and obvious differences. Immunol. Rev. 198:249-266.

Penttilä, M., Nevalainen, H., Rättö, M., Salminen, E., and Knowles, J. 1987. A versatile transformation system for the cellulolytic filamentous fungus Trichoderma reesei. Gene 61:155-164.

Pestka, J. J., and Smolinski, A. T. 2005. Deoxynivalenol: Toxicology and potential effects on humans. J. Toxicol. Environ. Health B Crit. Rev. 8:39-69.

Pfaffl, M. W., Horgan, G. W., and Dempfle, L. 2002. Relative expression software tool (REST) for group-wise comparison and statistical analysis of relative expression results in real-time PCR. Nucleic Acids Res. 30:e36.

Pinedo, C., Wang, C. M., Pradier, J. M., Dalmais, B., Choquer, M., Le Pêcheur, P., Morgant, G., Collado, I. G., Cane, D. E., and Viaud, M. 2008. Sesquiterpene synthase from the botrydial biosynthetic gene cluster of the phytopathogen Botrytis cinerea. ACS Chem. Biol. 3:791-801.

Punt, P. J., Oliver, R. P., Dingemanse, M. A., Pouwels, P. H., and van den Hondel, C. A. 1987. Transformation of Aspergillus based on the hygromycin B resistance marker from Escherichia coli. Gene 56:117-124.
Rossard, S., Luini, E., Pérault, J.-M., Bonmort, J., and Roblin, G. 2006. Early changes in membrane permeability, production of oxidative burst and modification of PAL activity induced by ergosterol in cotyledons of Mimosa pudica. J. Exp. Bot. 57:1245-1252.

Rossard, S., Roblin, G., and Atanassova, R. 2010. Ergosterol triggers characteristic elicitation steps in Beta vulgaris leaf tissues. J. Exp. Bot. 61:1807-1816.

Rubio, M. B., Domínguez, S., Monte, E., and Hermosa, R. 2012. Comparative study of Trichoderma gene expression in interactions with tomato plants using high-density oligonucleotide microarrays. Microbiology 158:119-128.

Spanova, M., Zweytick, D., Lohner, K., Klug, L., Leitner, E., Hermetter, A., and Daum, G. 2012. Influence of squalene on lipid particle/droplet and membrane organization in the yeast Saccharomyces cerevisiae. Biochim. Biophys. Acta 1821:647-653.

Ta, M. T., Kapterian, T. S., Fei, W., Du, X., Brown, A. J., Dawes, I. W., and Yang, H. 2012. Accumulation of squalene is associated with the clustering of lipid droplets. FEBS J. 279:4231-4244.

Takahashi, S., Kuzuyama, T., and Seto, H. 1999. Purification, characterization, and cloning of a eubacterial 3-hydroxy-3-methylglutaryl coenzyme A reductase, a key enzyme involved in biosynthesis of terpenoids. J. Bacteriol. 181:1256-1263.

Tholl, D., Boland, W., Hansel, A., Loreto, F., Röse, U. S. R., and Schnitzler, J. P. 2006. Practical approaches to plant volatile analysis. Plant J. 45:540-560.

Tijerino, A., Cardoza, R. E., Moraga, J., Malmierca, M. G., Vicente, F., Aleu, J., Collado, I. G., Gutiérrez, S., Monte, E., and Hermosa, R. 2011. Overexpression of the trichodiene synthase gene tri5 increases trichodermin production and antimicrobial activity in Trichoderma brevicompactum. Fungal Genet. Biol. 48:285-296.

Tucci, M., Ruocco, M., De Masi, L., De Palma, M., and Lorito, M. 2011. The beneficial effect of Trichoderma spp. on tomato is modulated by the plant genotype. Mol. Plant Pathol. 12:341-354.

Vandesompele, J., De Preter, K., Pattyn, F., Poppe, B., Van Roy, N., De Paepe, A., and Speleman, F. 2002. Accurate normalization of real-time quantitative RT-PCR data by geometric averaging of multiple internal control genes. Genome Biol. 3:research0034.1-research0034.11.

Vinale, F., Sivasithamparam, K., Ghisalberti, E. L., Marra, R., Woo, S., and Lorito, M. 2008. Trichoderma-plant-pathogen interactions. Soil Biol. Biochem. 40:1-10.

Williamson, B., Tudzynski, B., Tudzynski, P., and van Kan, J. A. 2007. Botrytis cinerea: The cause of grey mould disease. Mol. Plant Pathol. 8: 561-580. 